\title{
Divulgación de información financiera por parte de los gobiernos locales: Análisis de sus determinantes en Provincia de Buenos Aires
}

\author{
David José Gulayin*
}

Tesis de Maestría

Maestría en Finanzas Públicas Provinciales y Municipales

Universidad Nacional de la Plata

Director: Mg. Walter Rosales

Lector: Dr. Alberto Porto

Junio 2018

\footnotetext{
* Agradezco principalmente a: W. Rosales, M. Grotz, E. Versino, P. Torga, M. Garriga, J. Puig, H. Collacciani, M. López Armengol, E. De Giusti, S. Cerruti, M. Teilletchea, M. Soler, E. Soriano, mi familia y amigos. Los errores u omisiones son total responsabilidad del autor.

*Instituto de investigaciones y estudios contables (FCE-UNLP). El Plan Estratégico (período 2013-2017) del H. Tribunal de Cuentas de la Pcia. de Bs. As. (realizado con colaboración del BID) incluyó un programa de financiamiento de capacitaciones al personal entre las cuales se encuentra la presente.
} 


\begin{abstract}
La literatura ha indagado sobre la cantidad y calidad de la divulgación de información financiera o fiscal en internet por parte de los gobiernos locales y sobre sus determinantes. Sin embargo, para el caso de los gobiernos locales de la Provincia de Buenos Aires, existen escasas investigaciones sobre dichas cuestiones.

El presente trabajo realiza el relevamiento de la divulgación de la información financiera de los 135 gobiernos locales de la Provincia de Buenos Aires - Argentina - a través de internet, para los ejercicios económicos 2013 y 2016, e identifica los posibles determinantes que influyen en la divulgación para tales ejercicios.

La metodología utilizada, a los fines de aportar evidencia empírica a favor de las hipótesis planteadas, fue el planteo de modelos de regresiones logísticas múltiples, a través de los cuales se relacionó la variable divulgación de información financiera en internet con un conjunto de determinantes financieros, políticos y socioeconómicos.

Los resultados muestran que la divulgación de información financiera de los gobiernos locales bonaerenses no ha sufrido una variación significativa entre los periodos 2013 y 2016, alcanzando solo un 46,67\% y un 51,11\%, respectivamente. Por otro lado se ha encontrado evidencia a favor de que el tamaño de la población y del presupuesto, el acceso a internet y la no alineación política, se relacionan positiva y significativamente con la divulgación por parte de los gobiernos locales.
\end{abstract}

Palabras clave: Gobierno local, información financiera, divulgación, Provincia de Buenos Aires. 
Tabla de contenido

Introducción.....................................................................4

Capitulo I - Marco teórico.......................................................5

-Teorías generales: Principal agente, institucional, elección pública y legitimidad.

-Teorías de Federalismo Fiscal.

-Teorías sobre gobiernos locales: Teorema de Oates y eficiencia en la prestación de servicios.

-Principios de responsabilidad fiscal y su impacto en la legislación.

Capitulo II - Revisión de la literatura........................................13

-Literatura sobre la variable dependiente: Divulgación de información financiera.

-Literatura sobre las variables independientes.

Capitulo III - Hipótesis.................................................21

Capitulo IV - Metodología.....................................................23

-Medición de la variable dependiente: Divulgación de información financiera.

-Mediciones de las variables independientes.

-Técnicas de análisis de datos: Regresión logística múltiple.

Capitulo V - Análisis de datos.......................................................28

-Estadísticas descriptivas

-Matrices de correlación.

-Resultados de los modelos de regresión múltiple.

-Análisis de los resultados.

Conclusiones.......................................................................37

Referencias.....................................................................39 


\section{Introducción}

Los gobiernos locales de la Provincia de Buenos Aires ${ }^{2}$ (GLBA) administran una porción relevante de los recursos públicos, a pesar de lo cual sus correspondientes flujos de fondos han sido divulgados solo en algunos de sus sitios web oficiales. Dicha falla en el sistema político así como la heterogeneidad en la divulgación de información financiera ${ }^{3}$ (DIF) o fiscal durante los últimos años, ha sido escasamente estudiada por la literatura, lo cual motivó la presente investigación cuyo objetivo es responder, para los relevamientos realizados durante los años 2014 y 2017, la siguiente incógnita: ¿Cuáles son los determinantes de la DIF en internet por parte de los GLBA?

La cantidad y calidad de la DIF gubernamental en internet fue estudiada por la literatura mediante distintos modelos de medición y con distintos matices ${ }^{4}$. Asimismo la importancia otorgada a la transparencia de la información financiera como uno de los principios de responsabilidad fiscal, y la heterogeneidad de la cantidad y calidad de la DIF a lo largo de los distintos gobiernos locales generó interés en la academia, la cual estudió los posibles factores determinantes de la DIF (Laswad et al., 2005; Cárcaba García y García García, 2008; y, García García et al., 2016). Sin embargo, los resultados obtenidos son diversos y la evidencia aportada no es concluyente.

A los fines de responder la incógnita de la presente investigación, se utilizan modelos de regresión logística múltiple de manera de indagar si existe evidencia a favor de las hipótesis planteadas que relacionan a la DIF con las explicaciones clásicas brindadas por las diferentes teorías que intentan explicarla. El modelo planteado incluye como variable dependiente la "DIF de los GLBA" Ejercicio 2013 y Ejercicio 2016, y como variables independientes las siguientes: "situación financiera del gobierno local", "transferencias condicionadas de otras jurisdicciones", "competencia política", "alineación del GLBA con el gobierno provincial”, "tamaño", "ingreso promedio de los

\footnotetext{
${ }^{2}$ La Provincia de Buenos Aires es la provincia argentina más poblada y con mayor PBI. Se encuentra dividida en 135 Municipios gobernados por autoridades elegidas por sus ciudadanos.

${ }^{3}$ Divulgación de información financiera de los gobiernos locales se refiere a la puesta a disposición en el sitio web oficial, por parte de las autoridades locales, de la ejecución presupuestaria anual en donde los ciudadanos puedan acceder libremente al flujo de fondos anual de ingresos y egresos que administra el gobierno local con el objeto de informarse y monitorear su gestión.

${ }^{4}$ Entre estos estudios se encuentran los de Argañaraz et al., 2011; Nacke et al., 2012; Pando y Fernández Arroyo, 2013; Gómez Villegas y Montesinos Julve, 2014; Pagani y Pau, 2014; CENUD, 2015; y, Diéguez et al., 2015.
} 
ciudadanos" y "acceso a internet" las cuales se basan en el marco teórico de la presente investigación y en estudios empíricos, dentro de los cuales cabe destacar un estudio meta-analítico el cual identificó cinco factores clave que explican la divulgación de información financiera (Rodríguez Bolívar et al., 2013).

Identificar los determinantes de DIF puede contribuir a la implementación de estrategias que promuevan una mayor transparencia de la información financiera mediante el uso de tecnologías de información de manera de satisfacer las demandas sociales más efectiva y eficientemente, diseñando sistemas de información gubernamental más transparentes, democráticos y participativos. De este modo los ciudadanos estarán mejor informados y podrán tener un rol más activo en el seguimiento de las decisiones de las autoridades de los gobiernos locales, logrando una mejor administración local que contribuya al desarrollo social y económico.

En el primer capítulo de este trabajo de investigación se presenta el marco teórico utilizado describiendo los aportes realizados por la teoría de agencia y por otros enfoques complementarios (teoría institucional, con la teoría de la legitimidad, con la teoría de la elección pública, con los postulados del Teorema de la Descentralización de Oates y con los principios de responsabilidad fiscal); luego en el Capítulo II se realiza la revisión de la literatura en donde se citan las investigaciones empíricas más relevantes sobre los determinantes de la DIF; el siguiente capítulo presenta las hipótesis que surgen del marco teórico y de la revisión de la literatura. En el Capítulo IV se detalla el diseño general, la operacionalización de las variables, la selección de casos, las fuentes de datos, el trabajo de campo y las técnicas de análisis de datos a utilizar; y por último en el Capítulo V se realiza el análisis de datos y se exponen los resultados de la regresión logística junto con su análisis e interpretación.

\section{Capítulo I - Marco Teórico}

Preguntas como: ¿Es deseable que los gobiernos locales divulguen información financiera?, ¿Por qué puede existir opacidad en la divulgación de información?, ¿Cómo se explica el comportamiento de las autoridades gubernamentales respecto de la política de divulgación de información?, y ¿La legislación reglamenta la divulgación de información? presentan el marco de donde surge el interrogante de la presente investigación.

El presente capítulo plantea el marco teórico del presente trabajo, el cual se divide en 3 secciones: La primera sección hace referencia a la teoría de agencia como el 
marco para estudiar la DIF de los GLBA la cual se complementa con la teoría institucional, la teoría de la elección pública y la teoría de la legitimidad; la segunda sección destaca la importancia que le otorga a la información la segunda generación de teorías del federalismo fiscal y plantea a la DIF de los GLBA como una de las condiciones necesarias para una descentralización eficiente, en el marco del teorema de la descentralización de Oates; y, la tercera sección plantea los principios de responsabilidad fiscal, los cuales dan el marco a las reglas fiscales que regulan la DIF de los GLBA, y su impacto en la legislación.

\section{$\underline{\text { Teoría de agencia y otras complementarias }}$}

El análisis de la presente investigación se enmarca dentro de la teoría principalagente. Este enfoque es de utilidad, tal como lo indica Laswad et al., 2005, debido a que plantea la relación entre los ciudadanos de los Municipios de la Provincia de Buenos Aires como "Principales" y sus respectivos administradores del Municipio como "Agentes", siendo la divulgación de información financiera uno de los aspectos a estudiar en dicha relación.

Las relaciones entre los ciudadanos y sus gobernantes han sido analizadas dentro del marco de la teoría de la agencia (Zimmerman, 1977; Caba Pérez et. al, 2008; y Gómez Villegas y Montesinos Julve, 2014), ambos son sujetos racionales que buscan maximizar su propio beneficio y poseen intereses que pueden entrar en conflicto. En dicho marco la divulgación de información por parte de los gobernantes disminuye los costos de agencia. Cabe aclarar que los gobernantes desean ser reelegidos, y en el caso de la Provincia de Buenos Aires la legislación les permite ser reelectos indefinidamente, por lo cual podrían poseer incentivos para divulgar información. Por otro lado, la DIF disminuye la asimetría de información entre ciudadanos y autoridades gubernamentales, posibilitando el ejercicio del control y la toma de decisiones (Collin et al., 2009).

Los autores Gómez Villegas y Montesinos Julve (2014) y Rodríguez et al. (2013), asimismo, han planteado otras teorías en el marco teórico en el que se encuadra el estudio de la DIF de los GLBA. En tal sentido cabe mencionar a la teoría institucional, mediante la cual se plantea que las organizaciones no necesariamente asumen estructuras, procedimientos y técnicas como un medio para conseguir mayor racionalidad y eficiencia, sino que serían vías de los administradores para mostrar a la organización como apegada a los valores dominantes o a las expectativas sociales (Collin et al., 2009). 
Cabe mencionar también a la teoría de la elección pública (Buchanan, 1984), la cual señala que los votantes tienen un comportamiento económico racional, llevándolos a tomar decisiones de movilidad hacia las regiones con mayores beneficios. Los ciudadanos esperan servicios públicos de calidad en relación con la carga fiscal (Chan y Rubin, 1987 citado por Gómez Villegas y Montesinos Julve, 2014), en tal sentido la información financiera permite el seguimiento del uso de los impuestos y de las cargas asumidas por los ciudadanos. Asimismo cabe señalar que los gobernantes divulgan información no sólo para los votantes de su jurisdicción, sino para aquellos residentes en otras que pudieren ser futuros electores.

Rodríguez et al., 2013, hacen referencia también a la teoría de la legitimidad (Weber, 1978; Suchman, 1995), la cual establece que la legitimidad de las acciones de las organizaciones se encuentra influenciada por la divulgación de información a los stakeholders (Archel et al., 2009 citados por Rodríguez et al., 2013).

\section{$\underline{\text { Federalismo Fiscal }}$}

La literatura sobre federalismo fiscal plantea dos visiones, por un lado las teorías de primera generación suponen gobiernos benevolentes, de manera tal que no existen problemas de asimetrías de información, y por otro lado las teorías de segunda generación (SGT), en donde hay apartamientos y aparece la utilidad de información. En tal sentido Oates (2005) hace referencia a la expansión de la literatura sobre problemas de información y expresa lo siguiente:

"The outcomes from collective choice institutions depend in fundamental ways on the information that the various agents possess. In particular, in settings of asymmetric information, where some participants have knowledge of such things as preferences, cost functions, or effort, knowledge that is not available to other participants, the literature has shown us that optimal "procedures" or institutions are likely to be quite different from those in a setting of perfect information. The SGT is thus drawing heavily on much of thework in industrial organization and microeconomic theory that has explored these information issues ${ }^{5}$."

\footnotetext{
${ }^{5}$ Asimismo Oates agrega en nota al pie lo siguiente: “Boadway (1997) provides a rich and insightful discussion of the introduction of "imperfect information" into the corpus of public finance. In an important paper, Cremer, Estache and Seabright (1996) explicitly ask what we can learn about fiscal decentralization from the theory of the firm. In an interesting exchange, one reviewer of this paper contends that the primary roots of the SGT are to be found in the integration of imperfect information into
} 
Por otro lado Oates sostiene que en numerosos modelos de la SGT aparece un "trade off" en términos de "accountability" local versus coordinación de políticas centralizadas, en tal sentido expresa:

"In the wide range of models encompassing the SGT, the centralization versus decentralization tradeoff takes a variety of different forms. In several SGT models (e.g., Seabright, 1996), we find a tradeoff in terms of local "accountability" (sensitivity of outcomes to local preferences) versus a coordination of policies under centralization that serves to internalize interjurisidictional interdependencies."

En función de los argumentos expuestos cabe destacar la importancia que le otorga la literatura a los problemas de información.

\section{Gobiernos Locales}

Cabe citar los beneficios que plantea el Teorema de la Descentralización de Oates, los cuales suponen un modelo en el que los ciudadanos poseen acceso a la información financiera del gobierno local. Dicho teorema enfatiza las ganancias de bienestar derivadas del proceso de crear gobiernos locales autónomos, por ejemplo, la posibilidad de ajustar la provisión de bienes públicos a las preferencias de los ciudadanos de cada comunidad. A su vez, se reconocen otros beneficios tales como generar las oportunidades para la innovación y el desarrollo en la provisión de bienes públicos, y el estímulo a la mayor participación ciudadana y control político.

En línea con los argumentos normativos que destacan los beneficios de divulgar información cabe citar a una de las cuatro condiciones requeridas para que los gobiernos locales brinden servicios a su población y financien sus actividades en forma eficiente, es que los ciudadanos-votantes estén bien informados de modo que puedan evaluar el desempeño del gobierno municipal al momento de votar (Bird, 2001 citado por Garriga y Rosales, 2013), siendo las otras tres: que el área que recibe el beneficio cargue con los costos; que la responsabilidad de gastar coincida con la de recaudar, y

the analysis. Indeed, one can argue that with full and perfect information, there is no need for a public sector at all, for, in such a setting “. . . self-interested individuals would presumably use their knowledge to extract all possible pareto-superior gains from the economy because they have a mutual interest in doing so" (Tresh,1995, p. 19]. However, I have chosen to give the new political-economy literature jointbilling with imperfect information. There are a range of matters (e.g., Arrow problems, redistributive issues, etc.) that seem to transcend purely information problems." 
que la responsabilidad de recaudar coincida con la responsabilidad política. Estas son las cuatro dimensiones del "principio de correspondencia" que implican restricción presupuestaria y políticas fuertes en el nivel municipal, que los políticos sean votados por contribuyentes bien informados, que el político que gasta sea el que recauda, y los beneficios y costos se concentren en la región en la que el político es votado.

\section{$\underline{\text { Principios de responsabilidad fiscal }}$}

En línea con los argumentos normativos que plantean la necesidad de que las autoridades gubernamentales divulguen información, cabe destacar que la calidad de vida de los ciudadanos se encuentra relacionada con la calidad de gestión de las organizaciones públicas. La búsqueda de herramientas para el logro de una gestión que logre alcanzar los objetivos de la sociedad dio origen a establecer principios de responsabilidad fiscal, los cuales han sido estudiados por la literatura y comprenden todos los aspectos de la gestión pública, es decir, no solo se circunscriben a tópicos fiscales, presupuestarios y financieros, sino que se contempla la participación del ciudadano, la transparencia en la gestión, y mecanismos de control más claros. Dichos principios constituyen bases sobre las cuales se reglamentó la relación entre las autoridades gubernamentales, la ciudadanía y el resto de los actores con los que estas interactúan.

Bajo la premisa de alcanzar los ideales de la democracia representativa, la legislación ha avanzado hacia el cumplimiento de los principios de responsabilidad fiscal. Los organismos internacionales recomiendan la transparencia, porque teóricamente brindarían beneficios para la sociedad. De esta forma, para eliminar los incentivos perversos en el manejo de los recursos, una idea central es que los ciudadanos cuenten con información, y por ello se generan mecanismos para obligar e incentivar a los funcionarios a difundir los datos de calidad en forma oportuna. Aparece entonces el concepto de "rendición de cuentas", de forma que efectivamente los ciudadanos puedan ver si sus "agentes" están cumpliendo o no con su mandato y de esa forma modificar o no su voto en las elecciones.

En función de lo expuesto, cabe citar al Manual de Transparencia Fiscal del FMI del año 2001, el cual plantea cuatro principios generales: 1) Clara definición de funciones y responsabilidades (se refiere a la delimitación de la estructura y las funciones del gobierno, las responsabilidades del gobierno y las relaciones entre el gobierno y el resto de la economía); 2) Acceso del público a la información (destaca la 
importancia de publicar información fiscal completa en fechas claramente especificadas); 3) Transparencia en la preparación, ejecución y publicación del presupuesto (abarca el tipo de información que se hace pública sobre la preparación del presupuesto), y 4) Garantías de integridad (se refiere a la calidad de los datos fiscales y a la necesidad de una rigurosa evaluación independiente de esa información).

Por otro lado, para comprender la falta de transparencia y responsabilidad, Kopitz (2000) propone las siguientes cuatro posibles causas: 1) el ocultamiento deliberado con la intención de postergar y eludir un ajuste macroeconómico cuando el país lo necesita, 2) la dificultad de cumplir ciertas metas (especialmente metas cuantitativas de política económica), 3) la protección de intereses particulares como causa de la ocultación deliberada y 4) la falta de capacidad técnica para preparar y proveer datos oportunos y fiables. Dichas posibles causas propuestas por la literatura fundamentan parte de las hipótesis sobre determinantes de la divulgación de información financiera gubernamental para la presente investigación.

Cabe señalar que todos los principios planteados se refieren no solo a la transparencia, sino a las tradiciones e instituciones mediante las cuales es ejercida la autoridad en un país (Kaufmann, et al., 1999), es decir que comprende a los procesos por los cuales los gobernantes son seleccionados, monitoreados y reemplazados, la capacidad de los gobernantes para formular e implementar políticas públicas, y el respeto de los ciudadanos y el estado por las instituciones por las cuales ambos sectores interactúan. Por otro lado comprenden los siguientes aspectos: 1) "voice and external accountability" en el sentido que los ciudadanos y las instituciones democráticas pueden ejercer el control sobre el gobierno, 2) estabilidad política, libre de violencia, crimen y terrorismo, 3) efectividad del gobierno (teniendo en cuenta la calidad de los gobernantes, la burocracia y la provisión de servicios públicos), 4) la no existencia de exceso de regulación, 5) protección de los derechos de propiedad e independencia judicial y 6) control de la corrupción. Los aspectos citados son de suma utilidad para medir la divulgación de información financiera y para indagar sobre sus determinantes.

\section{Impacto de los principios de responsabilidad fiscal en la legislación}

Estos enfoques conceptuales a favor de la implementación de reglas fiscales, o de criterios de transparencia y responsabilidad fiscal, han derivado en recomendaciones de política que regulan el accionar de las autoridades gubernamentales y que han sido plasmadas en reglas fiscales en varios países (Rosales, 2005), como por ejemplo: 
1) La Fiscal Responsibility Act, promulgada en Nueva Zelanda en 1994, se convierte en un modelo internacional de transparencia y responsabilidad gubernamental. Según Kopitz (2000) después de un período difícil en la economía, Nueva Zelanda, por medio de esta legislación, dio un paso muy importante y concreto hacia la disciplina fiscal. Se establecieron criterios contables transparentes y se obligó al gobierno a informar al público y rendir cuenta de sus actos con cierta frecuencia.

2) A nivel municipal, Brasil también ha extendido el alcance de la ley de Responsabilidad Fiscal (Ley Complementaria Federal No 101 del 4 de mayo del 2000). Esta ley define reglas e indicadores para la gestión de los recursos públicos en relación a los ingresos, gastos, endeudamiento y patrimonio público. Entre los aspectos más importantes de la Ley de Responsabilidad Fiscal, se destacan: a) establecimiento de límites máximos para gastos con personal y endeudamiento público, b) definición de metas fiscales anuales para los tres (3) próximos ejercicios fiscales y c) mecanismo de control de los gastos públicos en períodos de elección.

3) En la Argentina, los principios de transparencia y responsabilidad fiscal propuestos por la Ley $\mathrm{N}^{\mathrm{o}} 25.917$ están presentes desde 1999 en la Ley $\mathrm{N}^{\mathrm{o}} 25.152$ de Administración de los Recursos Públicos, la cual contiene medidas para la administración de los recursos públicos, avanza sobre la eficiencia y calidad de la gestión pública, y sobre la información pública y de libre acceso, entre otros puntos.

Además de los ejemplos citados, las autoridades gubernamentales argentinas deben respetar la legislación nacional, provincial y doctrina que regulan cuestiones vinculadas con la "Divulgación de la Información". Algunos ejemplos de las mismas se citan a continuación:

○ Ley Nacional $N^{\circ} 25.917$ - Régimen Federal de Responsabilidad Fiscal y su reglamentación, y Ley Provincial N 13.295 (adhesión de la Pcia. de Buenos Aires a la Ley Nacional $\left.\mathrm{N}^{\mathrm{0}} 25.917\right)$ y su reglamentación.

○ Ley Nacional No 26.653 - Ley de accesibilidad de la información en las páginas web.

○ Ley Nacional N²7.275 de Acceso a la Información Pública.

○ Decreto Provincial №6769/1958 - Ley Orgánica de las Municipalidades.

○ Ley Provincial No 12.475 - Divulgación de información proveniente de órganos públicos del Estado Provincial - Acceso a documentos administrativos.

- El Decreto 1172/2003 de "Mejora de la calidad de la Democracia y de sus Instituciones" (5 Reglamentos: Acceso a la Información Pública; Audiencia 
Pública; Gestión de Intereses; Elaboración participativa de normas; Reuniones abiertas de los entes reguladores de servicios).

○ Resolución “Acordada General N ${ }^{\circ}$ 1/12" del Honorable Tribunal de Cuentas Pcia. de Bs. As.

- Recomendación Técnica del Sector Público $N^{o} 1$ de la Federación Argentina de Consejos Profesionales de Ciencias Económicas (FACPCE) - Marco Conceptual Contable para las Administraciones Públicas.

Cabe destacar que el Régimen Federal de Responsabilidad Fiscal (Ley Nacional $N^{\circ} 25.917$ y Ley Provincial $N^{\circ} 13.295$ de adhesión de la Pcia. de Buenos Aires a la Ley Nacional No 25.917) establece:

“ARTICULO $7^{\circ}$ - Cada provincia, la Ciudad Autónoma de Buenos Aires y el Gobierno nacional publicarán en su página web el Presupuesto Anual -una vez aprobado, o en su defecto, el Presupuesto Prorrogado, hasta tanto se apruebe aquél-y las proyecciones del Presupuesto Plurianual, luego de presentadas a las legislaturas correspondientes. Con un rezago de un (1) trimestre, difundirán información trimestral de la ejecución presupuestaria (base devengado y base caja), del stock de la deuda pública, incluida la flotante como así también los programas bilaterales de financiamiento, y del pago de servicios, detallando en estos tres (3) últimos casos el tipo de acreedor. A tales efectos se utilizarán criterios metodológicos compatibles con los establecidos en la ley $n^{\circ} 24.156$ y los clasificadores presupuestarios a los que se hiciera mención en el artículo $4^{\circ}$ de la presente ley. Asimismo, se presentará información del nivel de ocupación del sector público al 31 de diciembre y al 30 de junio de cada año con un rezago de un (1) trimestre, consignando totales de la planta de personal permanente y transitoria y del personal contratado, incluido el de los proyectos financiados por Organismos Multilaterales de Crédito. El Ministerio de Economía y Producción deberá elaborar y publicar en su página web la información antes detallada y la Jefatura de Gabinete de Ministros deberá publicar en su página web la consolidación de la misma."

Por otro lado en el caso de que las jurisdicciones no cumplan con dicha exigencia establece lo siguiente:

“ARTICULO 32. - El incumplimiento de las obligaciones establecidas por la presente ley dará lugar a sanciones, las cuales podrán consistir en lo siguiente, sin perjuicio de otras que el Consejo Federal de Responsabilidad Fiscal pudiera fijar al efecto:

i. Divulgación de la situación en todas las páginas web de las provincias, de la Ciudad Autónoma de Buenos Aires y del Gobierno nacional, en un apartado especial creado a tales efectos;

ii. Restricción del derecho a voto en el Consejo;

iii. Restricciones en el otorgamiento de nuevos beneficios impositivos nacionales destinados al sector privado ubicado en la jurisdicción que haya incumplido;

iv. Limitación en el otorgamiento de avales y garantías por parte del Gobierno nacional; 
v. Denegación de autorización para las operatorias de nuevos endeudamientos en los términos del artículo 25 de la presente ley;

vi. Limitación de las transferencias presupuestarias del Gobierno nacional con destino a las jurisdicciones que no sean originadas en impuestos nacionales coparticipables de transferencia automática."

Por otro lado cabe señalar que los Municipios de la Provincia de Buenos Aires se encuentran habilitados para adherir al citado Régimen Federal de Responsabilidad Fiscal. En la actualidad se encuentran adheridos formalmente, mediante la decisión de sus respectivos órganos legislativos (Concejos Deliberantes), un total de 132 Municipios sobre un total de 135 (Fuente: Ministerio de Economía de la Provincia de Buenos Aires ${ }^{6}$ ), por ende se encuentran obligados a divulgar información financiera en internet.

\section{Capítulo II - Revisión de la literatura}

El presente capítulo comienza con aclaraciones sobre el alcance, luego con el relevamiento de investigaciones sobre la variable dependiente de la presente investigación "Divulgación de información financiera (DIF)", seguido de un relevamiento de la literatura sobre determinantes de DIF, y finalmente se presentan las conclusiones, en las cuales se explicita la ausencia de literatura sobre determinantes para el caso de los GLBA y la heterogeneidad en los resultados de las investigaciones empíricas sobre determinantes de la DIF.

\section{$\underline{\text { Aclaraciones sobre el alcance }}$}

La divulgación de información financiera se encuentra inmersa en un conjunto amplio de aspectos complejos, respecto de los cuales cabe citar a la investigación empírica de Sanguinetti et al. 2015, los cuales en el marco de un trabajo sobre un estado más efectivo plantean, entre otras cuestiones, las siguientes ideas: “...Los registros administrativos son una herramienta esencial tanto para la gestión interna como para los mecanismos de control y rendición de cuentas externos; las ciudades latinoamericanas tienen mucho para mejorar en la difusión de información a través de sus portales web y en el uso más sofisticado de las TIC; el pluralismo en los medios de comunicación y un marco regulatorio saludable son defensas efectivas contra la captura de los medios de

\footnotetext{
${ }^{6}$ http://www.ec.gba.gov.ar/areas/Sub_Politica_Coord_Eco/PaginaConsejo/mapa_seccion8.php .
} 
comunicación; la información por sí sola no siempre logra movilizar a la ciudadanía; la participación ciudadana puede verse limitada cuando los ciudadanos desconocen cómo usar los mecanismos de participación o cuáles son sus derechos; y para que la participación ciudadana sea exitosa, es importante reforzar varios de los eslabones del control externo..."

La presente investigación profundiza el análisis de la DIF y sus determinantes, lo cual se encuentra relacionado con otras problemáticas como la calidad de la información financiera divulgada, la capacidad del ciudadano de interpretarla y la utilidad de la misma para el ciudadano.

\section{Divulgación de Información Financiera}

En el capítulo anterior se describen argumentos teóricos y empíricos acerca de la divulgación de información por parte de las autoridades locales. Por otro lado cabe señalar que la literatura ha encontrado evidencia a favor de que la falta de las tradiciones e instituciones mediante las cuales es ejercida la autoridad en un país o gobernabilidad no es neutra en términos de eficiencia y equidad. Kaufmann et al. (2003) encuentran evidencia de que los ingresos per cápita y la calidad de la gobernabilidad están estrechamente correlacionados entre los países. La evidencia empírica aportada por los diagnósticos de países también apoya la noción de que los mecanismos para promover la transparencia y la "voz" de los ciudadanos juegan un papel importante en mejorar la gobernabilidad de las instituciones en los países.

Desde otro punto de vista y en relación al efecto de la divulgación de información en el comportamiento de los contribuyentes del GLBA, cabe citar a Porto et al. 2010, quienes en el marco de un estudio sobre determinantes de la función de recaudación de los GLBA, incluyeron variables que pueden influir en la "moral tributaria" de los ciudadanos (por ejemplo: la información sobre el uso que se le da a los fondos recaudados) $)^{7}$. Los resultados de los modelos de estimación por mínimos cuadrados ordinarios aportan evidencia empírica a favor de la hipótesis que plantea que

\footnotetext{
${ }^{7}$ En esta línea construyeron un indicador simple del lado del presupuesto de las municipalidades que puede resultar de utilidad para explicar la recaudación municipal. El indicador consideraba si el municipio publica información actualizada sobre la recaudación de ingresos propios, memorias de gestión, presupuesto, ejecución presupuestaria, sueldos del personal y presupuesto participativo. El máximo valor que podía tomar este indicador es 6 y disminuye hasta cero cuando la municipalidad no publica ningún tipo de información del uso de la recaudación (todos los ítems poseían la misma ponderación).
} 
la variable independiente, divulgación de información, se encuentra relacionada en forma estadísticamente significativa y con signo positivo con la recaudación propia per cápita de los GLBA.

Dichos argumentos, dieron origen a la necesidad de medir la divulgación de información por parte de los gobiernos locales para lo cual existe un conjunto amplio de literatura al respecto (Gómez Villegas y Montesinos Julve, 2014; Pagani y Pau, 2014; y CENUD, 2015), la cual ha diseñado distintos modelos de medición de niveles de DIF en internet, que poseen diferentes matices vinculados posiblemente a la idiosincrasia de cada región y/o a aspectos subjetivos de los autores.

Para el caso de los Municipios argentinos más poblados existe literatura que realizó relevamientos sobre la DIF (Argañaraz et al., 2011; Nacke et al., 2012; Pando y Fernández Arroyo, 2013; y, Diéguez et al., 2015).

Respecto del caso de los 135 Municipios de la Provincia de Buenos Aires existe literatura (CENUD, 2015) que realizó un relevamiento sobre la cantidad y calidad de la divulgación de información por parte de los GLBA mediante el análisis de sus sitios oficiales (realizado entre el 15 de septiembre y el 18 de octubre de 2014). Dicho análisis, entre otros aspectos, analizaba una variable "transparencia" la cual incluía las siguientes preguntas (Cada pregunta positiva recibió un total de 5 puntos): ¿Existe un link al presupuesto/ejecución del gasto? ¿Existen declaraciones Juradas? ¿Existe acceso a digesto normativo? ¿Existen datos de contrataciones? ¿Existen datos de empleados públicos? ¿Existen informes de gestión?.

Otro relevamiento efectuado para el caso de los 135 Municipios de la Provincia de Buenos Aires (en el mes de noviembre del año 2014), fue realizado en el marco del trabajo final integrador que exige la Especialización de Administración Financiera y Control del Sector Publico por el autor (Gulayin, 2014), el cual relevó la DIF en internet por parte de los GLBA. Dicho relevamiento clasificó al total de los GLBA en 2 grupos, según si divulgaba su ejecución presupuestaria "Ejercicio 2013” en su sitio web o no.

Existe heterogeneidad en la forma de medir la divulgación de información financiera, un grupo de autores propone modelos binarios (Cárcaba García y García García, 2008; y Gulayin, 2014), otro grupo plantea una variable ordinal (CENUD 2015) y por último un grupo heterogéneo de autores utiliza distintos índices ponderados (Argañaraz et al., 2011; Nacke et al., 2012; Pando y Fernández Arroyo, 2013; y, Diéguez et al., 2015) que enriquecen la medición pero a su vez agregan un factor de subjetividad inevitable. Sin perjuicio de las diferentes metodologías de medición 
utilizadas, todos los autores convergen en la importancia de la cuestión y en la necesidad de mejorar los niveles de divulgación de información por parte de las autoridades gubernamentales.

\section{Determinantes de divulgación de Información Financiera}

La heterogeneidad de la cantidad y calidad de divulgación de información financiera a lo largo de los distintos gobiernos locales generó interés en la academia, la cual estudió los posibles determinantes de la DIF (Laswad et al., 2005; Cárcaba y García y García García, 2008; y, García García et al., 2016).

Respecto de los modelos aplicados para indagar si existe evidencia a favor de cuáles son los determinantes de la DIF, cabe señalar que el meta-análisis efectuado por Rodríguez et al. (2013), seleccionó una muestra de 39 investigaciones empíricas sobre determinantes de la DIF, en el cual surge que la mayoría de dichas investigaciones utilizaron modelos de regresión lineal múltiple, regresión logística, y probit, entre otros modelos.

No obstante la heterogeneidad de los resultados obtenidos por las diferentes investigaciones, la literatura tradicionalmente ha encontrado evidencia a favor de factores como: el nivel de la deuda del gobierno local; las transferencias intergubernamentales; y la competencia política, como determinantes vinculados a los supuestos de teorías institucionales (ya que se encuentran centrados en la gestión de las organizaciones y en la necesidad de rendir cuentas en el uso de los recursos públicos).

Por otro lado ha encontrado evidencia a favor de otros factores como el tamaño del gobierno local y el ingreso promedio de los ciudadanos, como determinantes vinculados a los supuestos de la teoría de la agencia (ya que se encuentran centrados en la demanda ciudadana de información financiera).

La heterogeneidad de los resultados a lo largo de los distintos países y regiones en donde se estudiaron los determinantes de la DIF y la falta de información a nivel subnacional en Argentina, y específicamente en la Provincia de Buenos Aires mediante un método sistemático-cuantitativo dio origen a la necesidad de realizar la presente investigación, la cual estudia el caso de los GLBA para el ejercicio económico anual 2013.

A continuación se describen los argumentos teóricos y las investigaciones empíricas que fundamentan las hipótesis planteadas en el siguiente capítulo: 
$\underline{\text { Situación financiera (Peso de los intereses sobre los ingresos) }}$

La literatura ha identificado a la situación financiera o peso de los intereses sobre los ingresos como uno de los determinantes de la DIF ${ }^{8}$. Rodríguez et al. (2013) plantean que la situación financiera (tomando como principal indicador la deuda municipal) es uno de los determinantes más comúnmente analizado en base a la teoría institucional. Dichos autores, en base a literatura previa (Baber, 1983; e Ingram, 1984 citados por Rodríguez et al., 2013), argumentan que la situación financiera está vinculada con la motivación del administrador público de transparentar la información. Esta variable se incluye en el análisis de la información financiera porque es un componente integral de la credibilidad financiera de las agencias gubernamentales frente a agentes externos, así como de la capacidad del gobierno para cumplir con sus compromisos de pago (Giroux y Deis, 1993 citados por Rodríguez et al., 2013), es decir, que los gestores públicos deben responder a mayores demandas de información para minimizar los conflictos de intereses entre acreedores, ciudadanos en general y los administradores del gobierno local (Baber y Gore, 2006; Baber y Sen, 1984; Gore 2004; Zimmerman, 1977 citados por Rodríguez et al., 2013).

Cárcaba García y García García (2008) plantean que bajo la teoría de agencia, con el fin de generar señales positivas sobre su desempeño, se ha incentivado a los gestores públicos a revelar información financiera pública como mecanismo para permitir el seguimiento de sus acciones.

Gómez Villegas y Julve Montesinos (2014) citan a Lüder (2002) el cual señaló que un estímulo determinante de las reformas de la gestión pública es el estrés financiero. Asimismo citan a Banker y Patton, (1987), Zimmerman, (1977) y Caba Pérez et al., (2008), destacando que encontraron que cuando una entidad pública tiene un mayor endeudamiento, existen incentivos para realizar una divulgación voluntaria de información, para buscar disminuir el costo de la deuda.

Los argumentos teóricos expuestos y los resultados empíricos sugieren que cuando las jurisdicciones estén más endeudadas (Laswad et al., 2005; Cárcaba García y García García, 2008; y Gómez Villegas y Montesinos Julve, 2014) y/o el peso de los intereses de deuda (Caba Pérez et al., 2008; y Gómez Villegas y Montesinos Julve,

\footnotetext{
${ }^{8}$ La literatura empírica que relaciona el endeudamiento con la DIF, ha verificado una relación positiva entre ambas, sin perjuicio de lo expuesto existe la posibilidad de que dicha relación posea signo negativo.
} 
2014) sean mayores probablemente divulguen mayor cantidad de información que las que se encuentran en menor medida.

\section{$\underline{\text { Transferencias de otras jurisdicciones }}$}

Las transferencias condicionadas de otras jurisdicciones también han sido identificadas como uno de los posibles determinantes de la DIF. Rodríguez et al. (2013), en base a literatura previa ${ }^{9}$, argumentan que se considera que estos fondos constituyen un factor esencial en la divulgación de información financiera, con el fin de permitir el control por parte de quienes los proveen. En los Estados Unidos, los investigadores han encontrado que la presencia de una proporción sustancial del financiamiento estatal por parte del gobierno federal puede servir para aumentar la influencia federal y el monitoreo de la divulgación financiera del Estado (Ingram y De Jong, 1987 citados por Rodríguez et al. 2013).

En línea con dichos argumentos Caba Pérez et al. (2008) en base a literatura previa (Ingram, 1984 y Lüder, 1992 citados por Caba Pérez et al. 2008) sugieren que las jurisdicciones que reciben más cantidad de fondos necesitan proveer más y mejores reportes a las jurisdicciones que les proveen dichos fondos. Dicha circunstancia puede influir en la divulgación de información financiera a otros usuarios.

\section{Competencia Política}

Se ha identificado a la competencia política en la jurisdicción como uno de los determinantes de la DIF, en tal sentido Rodríguez et al. (2013), en base a literatura previa $^{10}$, argumentan que la competencia política genera incentivos a los gobernantes para satisfacer las necesidades de los ciudadanos. En línea con lo expuesto señalan en base a literatura previa (Zimmerman, 1977; Giroux, 1989; Serrano, Rueda y Portillo, 2009 citados por Rodríguez et al. 2013) que existe evidencia de que los factores políticos influyen en las organizaciones públicas e incentivan a responder a las necesidades de sus votantes, ofreciéndoles una mayor cantidad de información. Los políticos buscan obtener el mayor número posible de votos y a mayor competencia mayor será el incentivo para demostrar la buena gestión llevada a cabo.

\footnotetext{
${ }^{9}$ Ingram 1984; Robbins y Austin, 1986; Ingram y De Jong, 1987; Copley 1991; y Lüder, 1994.

10 Baber, 1983; Baber y Sen, 1984; e Ingram, 1984.
} 


\section{$\underline{\text { Alineación política del gobierno local con el provincial }}$}

La literatura (Sanguinetti et al., 2001, y Barletta, 2012) ha identificado con frecuencia determinantes políticos relacionados con las conductas de las autoridades locales, uno de ellos es la alineación política entre el partido político/coalición política del gobierno local y el de la provincia. Los gobiernos locales alineados con el provincial probablemente reciban beneficios por dicha circunstancia.

Según Sanguinetti et al. 2001 la pertenencia a un mismo partido aumenta los incentivos de las administraciones provinciales a recurrir a la ayuda de los municipios en momentos de problemas financieros, hecho que parece corroborarse según los resultados hallados por Barletta (2012). Así, habría un comportamiento oportunista de los intendentes que comparten partido político con el gobernador, que incrementan el gasto sabiendo que la administración provincial les va a enviar recursos para financiar el aumento.

Respecto de la relación entre la alineación política y la divulgación de información financiera la literatura no ha indagado con frecuencia, no obstante los argumentos teóricos expuestos y los resultados empíricos sugieren que las jurisdicciones no alineadas políticamente con el gobierno provincial probablemente se comporten en forma diferente a las alineadas, incluso respecto de la predisposición de divulgar información financiera.

\section{$\underline{\text { Tamaño }}$}

Otro posible determinante de la DIF estudiado ha sido el tamaño de la jurisdicción. En la mayoría de los estudios empíricos se incluye el tamaño de la jurisdicción, tradicionalmente medido por la cantidad de habitantes o por los ingresos presupuestados (v. gr. Rodríguez et al., 2013; Styles y Tennyson, 2007; y Serrano et al., 2009).

Rodríguez et al. (2013) argumentan, en base a Baber (1983), que desde el punto de vista de la teoría de la agencia (Zimmerman, 1977) los grandes Municipios prestan servicios a un mayor número de ciudadanos y reciben más recursos, lo cual lleva a los ciudadanos a exigir un mayor volumen de información sobre el desempeño del gobierno. Asimismo citan a Serrano et al. (2009) y argumentan que la teoría de la legitimidad también sugiere una relación positiva entre tamaño y divulgación, ya que las diversas presiones para ser transparentes son mayores en los grandes Municipios. Desde otro enfoque dichos autores argumentan que la divulgación de información en internet 
representa una innovación y que las grandes jurisdicciones poseen mayores posibilidades de innovar que las pequeñas.

\section{Ingreso promedio de los ciudadanos}

La literatura ha identificado al nivel de ingreso de los ciudadanos de la jurisdicción local como uno de los determinantes de la DIF (Ingram, 1984; Styles y Tennyson, 2007; y Serrano et al., 2009). Serrano et al., 2009 señalan que el nivel tecnológico y los ingresos per cápita de la jurisdicción se encuentran relacionados positivamente y argumentan en línea con Ho (2002) que las ciudades con menor ingreso per cápita poseen menos probabilidades de realizar diseños web y menor demanda de servicios basados en la web. Asimismo, en base a literatura previa ${ }^{11}$ argumentan que en las jurisdicciones con ciudadanos que utilizan mayor cantidad de tecnologías de la información se crea el ambiente propicio para que los gobernantes ofrezcan mayor cantidad y calidad de servicios e información (incluida la información financiera) a los ciudadanos.

En línea con dichos argumentos Rodríguez et al. (2013) argumentan, en base a la literatura previa ${ }^{12}$, que las jurisdicciones con ciudadanos de mayores ingresos esperan recibir mejores servicios y una mayor cantidad de información para confirmar que los impuestos pagados se están aplicando eficazmente.

Los argumentos teóricos expuestos y los resultados empíricos sugieren que las jurisdicciones con un mayor ingreso per cápita probablemente divulguen mayor cantidad de información que las de menor ingreso.

\section{$\underline{\text { Acceso a Internet }}$}

La literatura ha identificado al acceso a internet de los ciudadanos de la jurisdicción local como uno de los determinantes de la DIF (Caba Pérez et al., 2008; y Debreceny et al., 2002).

Caba Pérez et al. (2008) argumentaban que la relación entre la variable penetración de internet con divulgación de información había sido ignorada en estudios previos, no obstante Debreceny et al. (2002) notó que el acceso a internet es una variable ambiental que, desde la perspectiva del usuario, crea demanda de información

\footnotetext{
${ }^{11}$ Cheng, 1992; Ingram, 1984; Ingram and Copeland, 1981; y Robbins and Austin, 1986.

${ }^{12}$ Ingram, 1984; Giroux, 1989; y Giroux y McLelland, 2003.
} 
financiera y desde el punto de vista del proveedor favorece la divulgación debido a una eficiente diseminación de información.

Los argumentos teóricos expuestos y los resultados empíricos sugieren que las jurisdicciones con mayor acceso a PC y/o a internet probablemente divulguen mayor cantidad de información.

\section{Capítulo III - Hipótesis}

A continuación se describen las hipótesis, basadas en el estudio de la literatura:

Los gobernantes poseen incentivos para divulgar mayor cantidad de información en busca de que sus acreedores perciban que el municipio es transparente y posee menor riesgo de incobrabilidad o mora, de manera de que así reduzcan las tasas de interés y costos de deuda. Por tal motivo se propone la siguiente hipótesis:

H1: A medida que aumentan los intereses de deuda en relación a los ingresos totales, se incrementa la probabilidad de divulgar información financiera pública.

Un mayor peso de las transferencias condicionadas recibidas por los GLBA del gobierno central, aumenta el monitoreo por parte del gobierno central sobre el uso de dichos recursos, pudiendo aumentar la presión para que se divulgue la ejecución de dichos recursos en los destinos aprobados. Por tal motivo se propone la siguiente hipótesis:

H2: A medida que aumentan las transferencias condicionadas de otras jurisdicciones en relación a los ingresos totales, se incrementa la probabilidad de divulgar información financiera pública.

Los políticos buscan obtener el mayor número posible de votos para poder ser reelectos, lo cual en un contexto de mayor competencia política aumenta los incentivos para mostrar la buena gestión llevada a cabo y la transparencia de sus cuentas y/o manejo de fondos. Por lo tanto, se propone la siguiente hipótesis:

H3: A medida que aumenta la competencia política se incrementa la probabilidad de divulgar información financiera pública.

La alineación política del gobierno local con la del gobierno provincial puede fortalecer al gobierno local, disminuyendo los incentivos para aumentar la divulgación de información financiera. Por tal motivo se propone la siguiente hipótesis: 
H4: La alineación política entre el gobernante local (intendente) y el gobernante de la provincia reduce la probabilidad de divulgar información financiera pública.

Los grandes municipios prestan servicios a un mayor número de ciudadanos y reciben más recursos, cuestión que lleva a los ciudadanos a exigir un mayor volumen de información sobre el desempeño del gobierno, y por lo tanto es probable que haya una mayor necesidad para que los grandes municipios proporcionen información. Por otro lado los Municipios grandes poseen una mayor escala que les permite una división de tareas más adecuada y una mayor profesionalización de sus áreas, facilitando la DIF en el sitio web oficial. Por tal motivo se propone la siguiente hipótesis:

H5: A medida que aumenta el tamaño se incrementa la probabilidad de divulgar información financiera pública.

Cuando los ingresos de los residentes aumentan, esperan recibir mejores servicios y una mayor cantidad de información para confirmar que los impuestos pagados se están aplicando eficazmente. Por tal motivo se propone la siguiente hipótesis:

H6: A medida que aumenta el ingreso promedio de los ciudadanos se incrementa la probabilidad de divulgar información financiera pública.

A medida que aumenta la cantidad de hogares con PC sobre el total de hogares de cada jurisdicción y la penetración de internet, aumenta la probabilidad de que las autoridades utilicen internet para divulgar información financiera y de que los ciudadanos accedan a dicha información a través de la web. Por tal motivo se propone la siguiente hipótesis:

H7: A medida que aumenta el acceso a internet se incrementa la probabilidad de divulgar información financiera pública. 


\section{Capítulo IV - Metodología}

El presente capítulo describe la operacionalización de las variables dependientes "DIF de los GLBA" y de sus posibles determinantes, y las técnicas de análisis de datos a utilizar para cada uno de los modelos planteados de variable dependiente.

\section{Divulgación de información financiera}

Todos los Municipios de la Provincia de Buenos Aires poseían en el año 2014 y 2017 sitios web oficiales a través de los cuales divulgaban información a distintos usuarios, no obstante solo algunos de ellos difundían información sobre los ingresos y egresos percibidos y/o devengados por el Municipio para el cumplimiento de las finalidades que determina la legislación bonaerense. Para la presente investigación se realizó la medición de la DIF de los GLBA en 2 ejercicios económicos distintos, año 2013 y año 2016.

Para el caso del ejercicio económico 2013 se utilizó el relevamiento realizado por Gulayin (2014) durante el mes de noviembre 2014, el cual relevó la divulgación de la ejecución presupuestaria en internet por parte de los GLBA. El relevamiento propio dividió el total de GLBA en 2 grupos, según divulgaran o no información financiera/fiscal en su sitio web. La cantidad y calidad de información financiera divulgada por los GLBA durante el 2014 fue heterogénea, dicha situación generó la necesidad de aplicar la siguiente regla: el grupo de quienes divulgan información está formado por aquellos GLBA que incluyen en su página web al menos la ejecución presupuestaria del último Ejercicio completo anual finalizado, en este caso: Ejercicio 2013.

Cabe aclarar que la ejecución presupuestaria se refiere a información sobre ingresos y egresos percibidos y/o devengados durante el ejercicio 2013 relacionados con los ingresos y egresos presupuestados para dicho periodo. En dicho marco se construyó una variable dependiente "DIF" (binaria), la cual toma el valor 1 si el GLBA divulga alguna información en su sitio web sobre ingresos y egresos en relación a lo autorizado por el Concejo Deliberante y toma el valor 0 en caso contrario.

La misma metodología fue aplicada para el ejercicio económico 2016, cuyo relevamiento se realizó durante el mes de marzo de 2017. 
Operacionalización de los determinantes

Con respecto al cálculo de las variables independientes, las mismas se detallan a continuación:

Situación Financiera: La situación financiera del gobierno local para un periodo en particular puede ser medida de diferentes maneras y con distintos matices. En tal sentido Laswad et al. (2005) utilizaron la relación del endeudamiento a largo plazo del gobierno local sobre el total del activo o patrimonio neto, Cárcaba García y García García (2008) la variación de pasivos financieros en el último presupuesto disponible per cápita, Gómez Villegas y Montesinos Julve (2014) el monto total del saldo de la deuda financiera dividido entre los ingresos totales (lo llaman apalancamiento) y la cifra que agrega los intereses de la deuda pública y las amortizaciones de la misma en el periodo / logaritmo neperiano del monto total de intereses y amortizaciones de deuda (lo llaman estrés financiero), y Caba Pérez et al. (2008) costo del fondeo del presupuesto anual / población.

Para el caso de la presente investigación se mide el "peso de la deuda" mediante la relación de los intereses de la deuda del ejercicio 2013 / los ingresos totales del ejercicio 2013 (Fuente: Cuenta Ahorro Inversión Financiamiento del ejercicio 2013 - Ministerio de Economía de la Pcia. Bs. As. $2014^{13}$ ), ya que no se encuentra disponible, para el caso de los gobiernos locales de la Provincia de Buenos Aires, el stock de deuda al cierre del ejercicio 2013 ni 2016, cuestión que plantea una restricción en las posibilidades de medir el endeudamiento.

Transferencias: El peso de las transferencias condicionadas de otras jurisdicciones (Nacional, Provincial y/u otros municipios) del gobierno local para un periodo en particular puede ser medido de diferentes maneras, por ejemplo Caba Pérez et al. (2008) han utilizado el valor de las transferencias corrientes y de capital. No obstante para el caso de la presente investigación, con el objeto de aislar el efecto tamaño, se mide la "participación de las transferencias condicionadas de otras jurisdicciones" mediante la relación entre el total de transferencias condicionadas de otras jurisdicciones recibidas en el ejercicio 2013 / los gastos totales del ejercicio 2013 (Fuente: Cuenta Ahorro Inversión Financiamiento del ejercicio 2013 - Ministerio de Economía de la Pcia. Bs. As. 2014).

\footnotetext{
${ }^{13}$ Ministerio de Economía de la Provincia de Buenos Aires. 2014. "Municipios de la provincia de Buenos Aires: Evolución de la situación económico financiera 2007-2013”.
} 
Para el ejercicio económico 2016 no se encontró disponible el gasto total por municipio durante el ejercicio 2016, por lo tanto no se incluyó en los modelos de dicho ejercicio.

Asimismo se midió la variable como transferencias condicionadas per cápita 2013 y 2016 (Fuente: Cuenta Ahorro Inversión Financiamiento del ejercicio 2013 Ministerio de Economía de la Pcia. Bs. As. 2014, sitio web del Ministerio de Economía de la Pcia. de Bs. As., y para la cantidad de habitantes INDEC - Censo Nacional de Población, Hogares y Viviendas 2010).

Competencia política: La competencia política del gobierno local para un periodo en particular puede ser medida de diferentes maneras. Laswad et al. (2005), Caba Pérez et al. (2008) han utilizado la relación de la cantidad de candidatos ganadores / total de cargos a ocupar del gobierno local, Cárcaba García y García García (2008) recurrieron al inverso del índice de Herfindahl-Hirschmann ${ }^{14}$, calculado a partir del porcentaje de votos obtenido por los distintos partidos políticos en las elecciones municipales, y Rodríguez Bolívar et al. 2013 citan autores que han utilizado la cantidad de sillas que ocupan los partidos minoritarios, el porcentaje de victorias, o índices de competencia política.

Para el caso de la presente investigación se construyó un índice que mide, para las elecciones de intendentes bonaerenses del año 2011 y 2015, la diferencia de votos entre la coalición política ganadora de las elecciones y la alternativa más votada sobre los votos de esta última, dando por resultado el porcentaje de votos obtenidos por el ganador por sobre los obtenidos por el segundo, por lo tanto cuanto más alto sea el porcentaje menor será la competencia política. La fuente de información es la que publica la Junta Electoral de la Provincia de Buenos Aires ${ }^{15}$.

Alineación política del gobierno local y el provincial: la alineación política entre el gobierno local y el provincial se medirá mediante una variable binaria la cual toma como valores para el ejercicio 2013: 1 para los municipios en donde gobierna la coalición Frente para la Victoria (FPV) y 0 para el resto, y para el ejercicio 2016: 1

\footnotetext{
14 Los autores aclaran: "En el ámbito de la Organización Industrial, el inverso de este índice es interpretado como el número equivalente de empresas de igual tamaño que darían lugar al mismo nivel de concentración que el existente en un sector. En nuestro caso, podría interpretarse como el número equivalente de partidos políticos con el mismo número de votos que generarían un nivel de competencia política similar al real."

${ }^{15} \mathrm{http}: / /$ www.juntaelectoral.gba.gov.ar/mapa-provincia-bsas.php .
} 
para los municipios en donde gobierna la coalición Cambiemos y 0 para el resto. La fuente de información es la que publica la Junta Electoral de la Provincia de Buenos Aires.

Tamaño: El tamaño del gobierno local para un periodo en particular puede ser medido de diferentes maneras. Laswad et al. (2005) han utilizado el total de activos o el total de ingresos, Cárcaba García y García García (2008), Gómez Villegas y Montesinos Julve (2014), y Caba Pérez et al. (2008) la cantidad de habitantes y logaritmo neperiano del número de habitantes.

Para el caso de la presente investigación se mide el tamaño de las jurisdicciones de la Provincia de Buenos Aires por la cantidad de habitantes del municipio/total de la provincia (Fuente: INDEC - Censo Nacional de Población, Hogares y Viviendas 2010) y los ingresos totales del GLBA Ejercicio 2013/Ingresos totales de todos los GLBA 2013 (Fuente: Ministerio de Economía de la Pcia. Bs. As. $2014^{16}$ ). Cabe señalar que el coeficiente de correlación entre los habitantes del municipio y los ingresos del municipio supera el $80 \%$, por lo tanto a pesar de que ambas variables midan cuestiones distintas, se tendrán en cuenta ambas en los modelos. Ingreso promedio de los ciudadanos: El nivel de ingreso de los habitantes bajo la administración del gobierno local para un periodo en particular puede ser medido de diferentes maneras. Rodríguez Bolívar et al. (2013) citan autores que han medido la riqueza a través del ingreso per cápita de los ciudadanos, y Gómez Villegas y Montesinos Julve (2014) utilizaron el Producto Interno Bruto del Departamento dividido por el Producto Interno Bruto Nacional. Para el caso de los habitantes bajo la administración de los gobiernos locales de la Provincia de Buenos Aires solo se encuentra disponible el índice de Necesidades Básicas Insatisfechas medido en el año 2010 (NBI - Fuente: Indec 2013 Censo Nacional de Población, Hogares y Viviendas 2010.), y el Producto Bruto Geográfico per cápita 2008 (Fuente: Porto y Lódola 2010).

Cabe aclarar que medir la riqueza de los habitantes no es una tarea simple ya que tanto el Producto Bruto Geográfico como el NBI, no miden la distribución del ingreso de los habitantes bajo la jurisdicción del gobierno local.

Acceso a internet: La disponibilidad de tecnología que permita el acceso a internet puede ser medida mediante diferentes variables. Gómez Villegas y Montesinos Julve

\footnotetext{
${ }^{16}$ Ministerio de Economía de la Provincia de Buenos Aires. 2014. "Municipios de la provincia de Buenos Aires: Evolución de la situación económico financiera 2007-2013”.
} 
(2014) utilizan el porcentaje de personas abonadas (suscritas) a servicio de internet en el hogar en el departamento, en relación al total poblacional.

Para la presente investigación se utilizará el porcentaje de hogares con PC sobre el total de hogares dado que es el dato que se encuentra disponible. El INDEC publica para el caso de los GLBA el "Cuadro H4-P. Provincia de Buenos Aires. Hogares por disponibilidad de bienes, según partido. Año 2010” el cual incluye la cantidad de hogares con disponibilidad de computadoras personales por municipio. El calculo que se realizó fue el siguiente cociente: Hogares con PC / Total de hogares. Cabe aclarar que los "Accesos residenciales a Internet por jurisdicción. Total del país. Años 2013 y 2014" publicados por el INDEC por provincia/Total población de la provincia, se encuentran correlacionados en un $85,9 \%$ con el porcentaje de hogares con PC que publica el Censo Nacional de Población, Hogares y Viviendas 2010 Censo del Bicentenario - Resultados definitivos Serie B No 2. Tomo 1 (Gráfico 8. Población de 3 años y más que utiliza computadora según provincia. Año 2010).

\section{Técnicas de análisis de datos}

Para el caso del modelo para el ejercicio económico 2013 y 2016 el contraste de las hipótesis formuladas en el apartado anterior se llevará a cabo mediante el empleo de técnicas de regresión logística múltiple de tipo transversal (cross-section) para los 135 Municipios de la Provincia de Buenos Aires - Ejercicio Económico 2013 (Relevamiento de sitios web de mayo 2014). Para ello se procedió a estimar un modelo donde la variable dependiente "divulgación de información financiera en internet" clasifica a los 135 municipios de la Provincia de Buenos Aires objeto de estudio en los dos grupos citados. La naturaleza nominal de la variable dependiente implica la necesidad de utilizar la regresión logística, para lo cual se procedió a calcular la probabilidad asociada a los valores de la variable dependiente nominal dicotómica Divulgación, a partir de un conjunto de variables predictoras, derivadas de las hipótesis enunciadas en el apartado anterior. La utilización de funciones de probabilidad permite superar el inconveniente asociado a la utilización de una variable dependiente nominal dicotómica que impide asumir la hipótesis de normalidad en un modelo de regresión ordinaria.

En base a lo planteado por Stock y Watson (2012), para cierto rango, los modelos de regresión lineal alcanzan resultados similares a los de regresión logística, por dicha razón fueron incluidos ambos en las tablas de resultados. 
Cabe aclarar que al ser un análisis del tipo corte transversal no existe el problema de autocorrelación, sin embargo puede existir correlación entre los términos de error de las distintas unidades de análisis (autocorrelación espacial). Sí se tuvieron en cuenta posibles problemas de heterocedasticidad, para lo cual en todas las estimaciones son de regresión logística múltiple con errores estándar robustos. Asimismo se realizó el control de la existencia de variables omitidas para todas las estimaciones de las regresiones logísticas múltiples.

\section{Capítulo V - Análisis de datos}

El presente capitulo presenta las principales estadísticas descriptivas de las variables dependiente e independientes, seguido de los resultados de los modelos de regresión lineal y logística, y del análisis de los mismos.

\section{Estadísticas descriptivas de las variables}

La Tabla 1 expone las estadísticas descriptivas de todas las variables dependientes e independientes utilizadas en todos los modelos de regresión lineal y logística múltiple.

Tabla 1. Estadísticas descriptivas de las variables

\begin{tabular}{|c|c|c|c|c|c|}
\hline Variables & Obs & Mean & Std. Dev. & Min & Max \\
\hline Variable dependiente binaria: DIF2013 & 135 & $46,67 \%$ & $50,07 \%$ & $0,00 \%$ & $100,00 \%$ \\
\hline Endeudamiento: Intereses/Ingresos Totales 2013 & 135 & $0,28 \%$ & $0,34 \%$ & $0,00 \%$ & $1,65 \%$ \\
\hline $\begin{array}{l}\text { Transferencias condicionadas: Transferencias condicionadas/ } \\
\text { gasto total } 2013\end{array}$ & 135 & $13,69 \%$ & $10,96 \%$ & $1,33 \%$ & $58,65 \%$ \\
\hline $\begin{array}{l}\text { Transferencias: Transferencias condicionadas 2013/ } \\
\text { Habitantes } 2010\end{array}$ & 134 & $\$ 743,38$ & $\$ 1.011,44$ & $\$ 20,72$ & $\$ 9.273,74$ \\
\hline $\begin{array}{l}\text { Competencia política: \% de votos del partido ganador por } \\
\text { encima del segundo } 2011\end{array}$ & 135 & $143,48 \%$ & $19,48 \%$ & $0,09 \%$ & $1128,84 \%$ \\
\hline Alineación política: FPV2011 & 135 & $69,63 \%$ & $46,16 \%$ & $0,00 \%$ & $100,00 \%$ \\
\hline Tamaño: Habitantes del municipio /Total de la provincia & 134 & $0,75 \%$ & $1,34 \%$ & $0,01 \%$ & $11,37 \%$ \\
\hline $\begin{array}{l}\text { Tamaño: Ingresos del municipio ejecutados en 2013/Total } \\
\text { ingresos }\end{array}$ & 135 & $0,74 \%$ & $0,96 \%$ & $0,04 \%$ & $5,68 \%$ \\
\hline Riqueza de los ciudadanos: NBI & 134 & $8,42 \%$ & $4,20 \%$ & $1,08 \%$ & $23,50 \%$ \\
\hline Riqueza de los ciudadanos: PBGpcap08 & 134 & $\$ 30.136,43$ & $\$ 13.258,54$ & $\$ 6.564,00$ & $\$ 84.369,00$ \\
\hline Hogares con PC/total de Hogares & 134 & $44,62 \%$ & $6,55 \%$ & $30,95 \%$ & $70,92 \%$ \\
\hline Variable dependiente binaria: DIF2017 & 135 & $51,11 \%$ & $50,17 \%$ & $0,00 \%$ & $100,00 \%$ \\
\hline $\begin{array}{l}\text { Transferencias: Transferencias condicionadas 2016/ } \\
\text { Habitantes } 2010\end{array}$ & 134 & $\$ 2.582,08$ & $\$ 1.577,58$ & $\$ 626,56$ & $\$ 7.031,84$ \\
\hline $\begin{array}{l}\text { Competencia política: \% de votos del partido ganador por } \\
\text { encima del segundo } 2015\end{array}$ & 135 & $44,69 \%$ & $43,86 \%$ & $1,07 \%$ & $2164,11 \%$ \\
\hline Alineación pol.: Cambiemos 2015 & 135 & $48,15 \%$ & $50,15 \%$ & $0,00 \%$ & $100,00 \%$ \\
\hline
\end{tabular}

*En los casos de observaciones de 134, se aclara que el Municipio de Lezama (recibió su autonomía el 22/12/2009) fue creado con posterioridad a la medición de la variable. 
La Tabla 1 expone una alta heterogeneidad en los valores que asumen las variables para cada GLBA. Cabe señalar que la variable dependiente DIF de los GLBA no tuvo un cambio significativo entre el relevamiento de 2014 y 2017, pasando de un $46,67 \%$ a un $51,11 \%$. Respecto de la variable que mide intereses sobre ingresos, surgen valores muy bajos durante el ejercicio 2013, teniendo como máximo un valor del $1,65 \%$. Las transferencias condicionadas per cápita aumentaron significativamente entre los ejercicios 2013 y 2016.

La competencia política aumentó significativamente si comparamos las elecciones 2011 con las 2015. La alineación política sufrió un cambio significativo ya que cambió la coalición política ganadora a nivel provincial, lo cual impactó en una reducción de la cantidad de GLBA gobernados por coaliciones políticas alineadas con la provincial.

Las Tablas 2 y 3 exponen las matrices de correlación entre todas las variables utilizadas en los modelos de manera de identificar posibles problemas de multicolinealidad. En los casos en donde el coeficiente de correlación superó el valor 0,30 se corrieron los modelos con y sin la variable de manera de asegurar la robustez de los resultados de los modelos.

Tabla 2. Matriz de correlación (Ejercicio 2013)

\begin{tabular}{|c|c|c|c|c|c|c|c|c|c|c|c|}
\hline DIF 2014 & 1 & & & & & & & & & & \\
\hline \% T.C.2013 & -0.1066 & -0.1530 & 1 & & & & & & & & \\
\hline $\begin{array}{l}\text { T. C. per cap } \\
2013\end{array}$ & -0.0582 & -0.0722 & $0.6446^{*}$ & 1 & & & & & & & \\
\hline $\begin{array}{l}\text { Alıneacion } \\
\text { Política }\end{array}$ & -0.1571 & -0.0852 & $0.3895^{*}$ & $0.2513^{*}$ & $0.3225^{*}$ & 1 & & & & & \\
\hline \% Población & $0.2093 *$ & -0.0942 & 0.0131 & $-0.1779^{*}$ & $0.5061^{*}$ & 0.0756 & 1 & & & & \\
\hline$\%$ Ingresos & $0.2752^{*}$ & -0.0910 & 0.0894 & -0.0579 & $0.4752 *$ & 0.0077 & $0.8893 *$ & 1 & & & \\
\hline NBI & 0.0708 & -0.1151 & $0.3409^{*}$ & 0.0315 & $0.4921 *$ & $0.3029 *$ & $0.3729 *$ & $0.3070 *$ & 1 & & \\
\hline PBGpcap08 & -0.0754 & 0.0260 & $-0.2403 *$ & -0.0288 & $-0.2836^{*}$ & $-0.2435^{*}$ & -0.3093 * & $-0.2300^{*}$ & $-0.5079 *$ & 1 & \\
\hline
\end{tabular}


Tabla 3. Matriz de correlación (Ejercicio 2016)

\begin{tabular}{|c|c|c|c|c|c|c|c|c|c|}
\hline & DIF 2017 & $\begin{array}{c}\text { T. C. per cap } \\
2016\end{array}$ & Compe. Poli & $\begin{array}{l}\text { Alineación } \\
\text { Política }\end{array}$ & $\begin{array}{c}\% \\
\text { Población }\end{array}$ & $\begin{array}{c}\% \\
\text { Ingresos }\end{array}$ & NBI & PBGpcap08 & $\%$ H. con PC \\
\hline DIF 2017 & 1 & & & & & & & & \\
\hline T. C. per cap 2016 & 0.0551 & 1 & & & & & & & \\
\hline Compe. Poli & 0.0663 & -0.0778 & 1 & & & & & & \\
\hline Alineación Política & 0.1120 & 0.1294 & -0.0190 & 1 & & & & & \\
\hline \% Población & 0.1258 & $-0.4650 *$ & $0.1854^{*}$ & -0.1013 & 1 & & & & \\
\hline$\%$ Ingresos & 0.1565 & $-0.4919 *$ & $0.2161 *$ & -0.0502 & $0.8893 *$ & 1 & & & \\
\hline NBI & 0.0068 & $-0.4235 *$ & -0.0187 & $-0.2219^{*}$ & $0.3729 *$ & $0.3070 *$ & 1 & & \\
\hline PBGpcap08 & 0.0368 & $0.3495^{*}$ & $0.2153 *$ & $0.1790^{*}$ & $-0.3093 *$ & $-0.2300 *$ & $-0.5079 *$ & 1 & \\
\hline$\%$ H. con PC & 0.0495 & $-0.4606 *$ & $0.2514 *$ & 0.0947 & $0.2671 *$ & $0.4218^{*}$ & $-0.2412 *$ & 0.1693 & 1 \\
\hline
\end{tabular}

$\underline{\text { Resultados de los modelos de regresión lineal y logística múltiple }}$

La medición de los posibles determinantes, identificados por la literatura previa, que serán tenidos en cuenta para la presente investigación, en ciertos casos, fue realizada mediante más de una variable. Tal es el caso del determinante: "transferencias" el cual fue medido por las transferencias condicionadas 2013 sobre total del gasto del GLBA 2013 y por el total de transferencias condicionadas por habitante 2013; "tamaño" el cual fue medido a través de la población del municipio y del total de ingresos del gobierno local del periodo; e "ingresos promedio" el cual fue medido a través del Producto Bruto Geográfico per cápita del año 2008 y por el índice de Necesidades Básicas Insatisfechas del año 2010.

Por dichas razones sumado a la existencia de altos coeficientes de correlación entre las variables del modelo que pudieren alterar los resultados de las regresiones lineales y logísticas múltiples, se plantearon los siguientes modelos: Modelo 1.1: incluye todos los determinantes planteados en las hipótesis, salvo H7 (acceso a internet) con el objeto de separar el efecto "tamaño" del efecto "acceso a internet"; Modelo 1.2: igual al modelo 1.1 pero se reemplazan las variables utilizadas para los factores "transferencias", "tamaño" e "ingresos promedio"; y Modelo 1.3: incluye todos los determinantes planteados en las hipótesis.

Cabe señalar que los modelos de regresión logística son de muy compleja interpretación. La naturaleza no lineal de la relación entre las variables independientes y la dependiente, y la complicada transformación de esta última en un logit (o logaritmo de las chances), hacen que los coeficientes obtenidos resulten de ardua lectura aún para personas familiarizadas con el análisis de regresión múltiple por mínimos cuadrados. Por tal motivo y en base a lo señalado por Stock y Watson (2012) en referencia a que en 
cierto rango de valores los resultados de las probabilidades de modelos de regresión lineal y los de regresión logística dan valores similares, se expone la Tabla 4, la cual incluye los resultados de los citados modelos. Cabe mencionar que los mismos poseen un Pseudo $R 2$ menor al 12\%, cuestión que indica un bajo nivel de explicación de la variabilidad, lo cual puede encontrarse relacionado con que no se han tenido en cuenta otros posibles determinantes de la DIF.

Tabla 4. Estimación de los determinantes de la probabilidad de la DIF (Ejercicio económico 2013). Modelo lineal de probabilidad y Logístico.

\begin{tabular}{|c|c|c|c|c|c|c|}
\hline \multirow[b]{2}{*}{ Variables } & \multicolumn{2}{|c|}{ Modelo 1.1} & \multicolumn{2}{|c|}{ Modelo 1.2} & \multicolumn{2}{|c|}{ Modelo 1.3} \\
\hline & Linear & Logit & Linear & Logit & Linear & Logit \\
\hline \multirow{2}{*}{ Intereses } & 10.78 & 44.65 & 11.93 & 53.97 & 8.916 & 37.84 \\
\hline & (12.01) & (51.04) & (11.51) & (50.37) & (11.15) & (51.18) \\
\hline \multirow[t]{2}{*}{ \% Т.C.2013 } & -0.280 & -1.330 & & & -0.257 & -1.138 \\
\hline & $(0.436)$ & (1.983) & & & $(0.442)$ & (1.982) \\
\hline \multirow[t]{2}{*}{ Comp. Poli. } & 0.0118 & 0.0323 & 0.00260 & -0.00899 & 0.00632 & 0.0211 \\
\hline & $(0.0247)$ & $(0.111)$ & $(0.0240)$ & $(0.111)$ & $(0.0242)$ & $(0.110)$ \\
\hline \multirow[t]{2}{*}{$\begin{array}{l}\text { Alineación } \\
\text { Política }\end{array}$} & $-0.185^{*}$ & $-0.734 *$ & $-0.181^{*}$ & $-0.775^{*}$ & -0.145 & -0.635 \\
\hline & $(0.103)$ & $(0.442)$ & $(0.103)$ & $(0.446)$ & $(0.104)$ & $(0.455)$ \\
\hline \multirow[t]{2}{*}{ \% Población } & $6.860 * *$ & $41.86^{*}$ & & & 3.833 & 19.10 \\
\hline & (3.156) & (24.88) & & & (2.883) & (18.94) \\
\hline \multirow[t]{2}{*}{ NBI } & 0.00723 & 0.0269 & & & 0.0167 & 0.0719 \\
\hline & $(0.0121)$ & $(0.0524)$ & & & $(0.0126)$ & $(0.0573)$ \\
\hline \multirow[t]{2}{*}{$\begin{array}{l}\text { T. C. per cap } \\
2013\end{array}$} & & & $1.17 \mathrm{e}-06$ & $6.97 \mathrm{e}-06$ & & \\
\hline & & & $(4.20 \mathrm{e}-05)$ & $(0.000167)$ & & \\
\hline \multirow[t]{2}{*}{$\%$ Ingresos } & & & $13.74 * * *$ & $73.29 * *$ & & \\
\hline & & & $(4.513)$ & (33.19) & & \\
\hline \multirow[t]{2}{*}{ PBGpcap08 } & & & $-2.05 \mathrm{e}-06$ & $-8.70 \mathrm{e}-06$ & & \\
\hline & & & $(3.27 \mathrm{e}-06)$ & $(1.49 \mathrm{e}-05)$ & & \\
\hline \multirow[t]{2}{*}{ \% H.con PC } & & & & & $1.674 * * *$ & $7.532 * *$ \\
\hline & & & & & $(0.596)$ & (3.167) \\
\hline \multirow[t]{2}{*}{ Constant } & $0.477 * * *$ & -0.123 & $0.517 * * *$ & 0.0186 & -0.344 & $-3.762 * *$ \\
\hline & $(0.116)$ & $(0.480)$ & $(0.158)$ & $(0.712)$ & $(0.331)$ & (1.643) \\
\hline Observations & 134 & 134 & 134 & 134 & 134 & 134 \\
\hline $\mathrm{R}$-squared & 0.084 & 0.0672 & 0.107 & 0.0856 & 0.120 & 0.0921 \\
\hline
\end{tabular}

Robust standard errors in parentheses

$* * * \mathrm{p}<0.01, * * \mathrm{p}<0.05, * \mathrm{p}<0.1$

Respecto a los resultados de los modelos de regresión logística cabe exponer la transformación de los mismos de manera que sea posible interpretar la probabilidad asociada a cada variable relacionada con la DIF en forma estadísticamente significativa. Para el caso del determinante "Alineación política" Modelo 1.1 y 1.2 los resultados son: 
Predictive margins

Model VCE : Robust

Expression : $\operatorname{Pr}(\mathrm{DIF} 14), \operatorname{predict}()$

\begin{tabular}{cllllll}
\hline $\begin{array}{c}\text { Alineación } \\
\text { Política }\end{array}$ & Margin & $\begin{array}{l}\text { Delta-method } \\
\text { Std. Err. }\end{array}$ & $\mathrm{z}$ & $\mathrm{P}>\mathrm{z}$ & {$[95 \%$ Conf. } & Interval] \\
\hline 0 & .5873066 & .0788144 & 7.45 & 0.000 & .4328332 & .74178 \\
1 & .4167213 & .053829 & 7.74 & 0.000 & .3112184 & .5222242 \\
\hline
\end{tabular}

\begin{tabular}{cclllll}
\hline $\begin{array}{c}\text { Alineación } \\
\text { Política }\end{array}$ & Margin & $\begin{array}{l}\text { Delta-method } \\
\text { Std. Err. }\end{array}$ & $\mathrm{z}$ & $\mathrm{P}>\mathrm{z}$ & {$[95 \%$ Conf. } & Interval $]$ \\
\hline 0 & .5920306 & .0767241 & 7.72 & 0.000 & .441654 & .7424071 \\
1 & .4167366 & .0531696 & 7.84 & 0.000 & .3125261 & .5209471 \\
\hline
\end{tabular}

En función de lo expuesto se comprueba que los resultados de los modelos de regresión lineal y logística aportan evidencia de que encontrarse alineado políticamente reduce la probabilidad de divulgar información financiera en internet para el ejercicio 2013 en un rango del $17 \%$ al $18,5 \%$.

Para el caso de los determinantes "tamaño" (participación de la Población del GLBA sobre el total y participación de los ingresos presupuestarios del GLBA sobre el total) y "acceso a internet" (participación de hogares con PC sobre el total), los resultados de los modelos de regresión logística multiple $(1.1,1.2$ y 1.3$)$ se exponen a continuación de manera que se explicite la variación de la probabilidad para cada tramo (del minimo a la media y de la media al máximo) de la variable independiente:

\begin{tabular}{|c|c|c|}
\hline \multicolumn{2}{|c|}{$\begin{array}{l}\text { Modelo } 1.1 \\
\text { Estimacion Población (alineado) }\end{array}$} & \multirow[b]{2}{*}{$\begin{array}{c}\text { Variación } \\
6,86 \% \\
61,27 \% \\
\end{array}$} \\
\hline $\begin{array}{l}\text { Min } \\
\text { Mean } \\
\text { Max }\end{array}$ & $\begin{array}{l}0,0001 \\
0,0075 \\
0,1137\end{array}$ & \\
\hline \multicolumn{2}{|c|}{ Estimacion Población (no alineado) } & Variación \\
\hline $\begin{array}{l}\text { Min } \\
\text { Mean } \\
\text { Max }\end{array}$ & $\begin{array}{l}0,0001 \\
0,0075 \\
0,1137\end{array}$ & $\begin{array}{c}7,73 \% \\
44,28 \%\end{array}$ \\
\hline \multicolumn{2}{|c|}{$\begin{array}{l}\text { Modelo } 1.2 \\
\text { Estimacion Ingresos (alineado) }\end{array}$} & Variación \\
\hline $\begin{array}{l}\text { Min } \\
\text { Mean } \\
\text { Max } \\
\end{array}$ & $\begin{array}{l}0,0004 \\
0,0074 \\
0,0568 \\
\end{array}$ & $\begin{array}{l}12,09 \% \\
52,12 \%\end{array}$ \\
\hline \multicolumn{2}{|c|}{ Estimacion Ingresos (no alineado) } & Variación \\
\hline $\begin{array}{l}\text { Min } \\
\text { Mean } \\
\text { Max } \\
\end{array}$ & $\begin{array}{l}0,0004 \\
0,0074 \\
0,0568 \\
\end{array}$ & $\begin{array}{l}12,47 \% \\
34,83 \%\end{array}$ \\
\hline \multicolumn{2}{|c|}{$\begin{array}{l}\text { Modelo } 1.3 \\
\text { Estimacion \% PC }\end{array}$} & Variación \\
\hline $\begin{array}{l}\text { Min } \\
\text { Mean } \\
\text { Max } \\
\end{array}$ & $\begin{array}{l}0,3095 \\
0,4462 \\
0,7092 \\
\end{array}$ & $\begin{array}{l}20,81 \% \\
42,81 \%\end{array}$ \\
\hline
\end{tabular}


La Tabla 5 expone los resultados de los citados modelos para el ejercicio 2016, ajustados por las limitaciones de acceso a bases de datos más actualizadas (intereses/ingreso 2016 y transferencias condicionadas/gasto total 2016). Dichos modelos poseen un Pseudo $R 2$ menor al 6\%, por lo tanto cabe señalar que los mismos también poseen un bajo nivel de explicación de la variabilidad, lo cual puede encontrarse relacionado con que no se han tenido en cuenta otros posibles determinantes de la DIF.

Tabla 5. Estimación de los determinantes de la probabilidad de la DIF (Ejercicio económico 2016). Modelo lineal de probabilidad y Logístico.

\begin{tabular}{|c|c|c|c|c|c|c|}
\hline \multirow[b]{2}{*}{ Variables } & \multicolumn{2}{|c|}{ Modelo 2.1} & \multicolumn{2}{|c|}{ Modelo 2.2} & \multicolumn{2}{|c|}{ Modelo 2.3} \\
\hline & Linear & Logit & Linear & Logit & Linear & Logit \\
\hline \multicolumn{6}{|l|}{ T. C. per cap } & 0.000272 \\
\hline 2016 & $(3.48 \mathrm{e}-05)$ & $(0.000157)$ & $(3.48 \mathrm{e}-05)$ & $(0.000148)$ & $(4.24 \mathrm{e}-05)$ & $(0.000181)$ \\
\hline \multirow[t]{2}{*}{ Comp. Poli. } & 0.0431 & 0.157 & 0.0241 & 0.0899 & 0.0249 & 0.101 \\
\hline & $(0.101)$ & $(0.425)$ & $(0.107)$ & $(0.466)$ & $(0.106)$ & $(0.444)$ \\
\hline \multicolumn{7}{|l|}{ Alineación } \\
\hline \multirow[t]{2}{*}{ Política } & 0.128 & 0.516 & 0.110 & 0.458 & 0.121 & 0.499 \\
\hline & $(0.0882)$ & $(0.362)$ & $(0.0870)$ & $(0.361)$ & $(0.0886)$ & $(0.363)$ \\
\hline \multirow[t]{2}{*}{ \% Población } & $6.991 * *$ & $39.31^{*}$ & & & $6.408^{* *}$ & $34.81^{*}$ \\
\hline & $(2.688)$ & $(21.55)$ & & & (2.538) & (20.71) \\
\hline \multirow[t]{2}{*}{ NBI } & 0.00298 & 0.00988 & & & 0.00923 & 0.0330 \\
\hline & $(0.0124)$ & $(0.0513)$ & & & $(0.0145)$ & $(0.0610)$ \\
\hline \multirow[t]{2}{*}{$\%$ Ingresos } & & & $11.97 * *$ & $55.25^{* *}$ & & \\
\hline & & & $(4.758)$ & $(27.78)$ & & \\
\hline \multirow[t]{2}{*}{ PBGpcap08 } & & & $4.76 \mathrm{e}-07$ & $2.18 \mathrm{e}-06$ & & \\
\hline & & & $(3.73 \mathrm{e}-06)$ & $(1.54 \mathrm{e}-05)$ & & \\
\hline \multirow[t]{2}{*}{ \% H.con PC } & & & & & 0.740 & 2.698 \\
\hline & & & & & $(0.943)$ & $(4.140)$ \\
\hline \multirow[t]{2}{*}{ Constant } & 0.243 & -1.160 & 0.224 & $-1.196 *$ & -0.172 & -2.652 \\
\hline & $(0.181)$ & $(0.786)$ & $(0.141)$ & $(0.620)$ & $(0.555)$ & $(2.401)$ \\
\hline Observations & 134 & 134 & 134 & 134 & 134 & 134 \\
\hline $\mathrm{R}$-squared & 0.049 & 0.0392 & 0.058 & 0.0406 & 0.054 & 0.0444 \\
\hline
\end{tabular}

Para el caso de los determinantes "tamaño" (participación de la Población del GLBA sobre el total y participación de los ingresos presupuestarios del GLBA sobre el total) los resultados de los modelos de regresión logística multiple $(2.1,2.2$ y 2.3$)$ se 
exponen a continuación de manera que se explicite la variación de la probabilidad para cada tramo (del mínimo a la media y de la media al máximo) de la variable independiente ${ }^{17}$ :

\begin{tabular}{|c|c|c|}
\hline \multicolumn{2}{|c|}{$\begin{array}{l}\text { Modelo } 2.1 \\
\text { Estimación Población }\end{array}$} & \multirow{2}{*}{$\begin{array}{c}\text { Variación } \\
5,69 \% \\
66,85 \%\end{array}$} \\
\hline $\begin{array}{l}\text { Min } \\
\text { Mean } \\
\text { Max } \\
\end{array}$ & $\begin{array}{l}0,0001 \\
0,0075 \\
0,1137 \\
\end{array}$ & \\
\hline \multicolumn{3}{|c|}{ Modelo 2.2} \\
\hline $\begin{array}{l}\text { Min } \\
\text { Mean } \\
\text { Max } \\
\end{array}$ & $\begin{array}{l}0,0004 \\
0,0074 \\
0,0568 \\
\end{array}$ & $\begin{array}{c}7,66 \% \\
56,18 \%\end{array}$ \\
\hline \multicolumn{3}{|c|}{ Modelo 2.3} \\
\hline $\begin{array}{l}\text { Min } \\
\text { Mean } \\
\text { Max }\end{array}$ & $\begin{array}{l}0,0001 \\
0,0075 \\
0,1137\end{array}$ & $\begin{array}{c}1,78 \% \\
70,30 \%\end{array}$ \\
\hline
\end{tabular}

\section{$\underline{\text { Análisis de los resultados }}$}

Los resultados de los modelos de regresión lineal y logística múltiple, aplicados al ejercicio económico 2013 y 2016, no aportan evidencia acerca de la existencia de una relación estadísticamente significativa entre la variable dependiente y la independiente para el caso de las Hipótesis $\mathrm{N}^{\circ} 1,2,3$, y 6. Cabe aclarar que el efecto en la variable dependiente de las variables que no son estadísticamente significativas no es relevante, por lo tanto no se puede predecir la dirección de la relación (más allá de que en conjunto por el test chi, pueda rechazarse la hipótesis conjunta de que todos los coeficientes son distintos de cero). Distinto es el caso de las siguientes Hipótesis:

H4: La alineación política entre el gobierno local y el provincial disminuye la probabilidad de divulgar información financiera pública: Los resultados de los modelos de regresión lineal y logística (1.1 y 1.2), para el ejercicio 2013 aportan evidencia de que la alineación política entre el gobernante local y el provincial posee una relación negativa y estadísticamente significativa con la con la variable DIF ${ }^{18}$,

17 El cálculo de los valores se realizó con la siguiente formula: Variación de 1/(1+exp(constant+coef*min o mean o max)), en base al capítulo 11 de Stock y Watson (2012).

18 Cabe aclarar que los coeficientes originales de la Tabla 4 y 5 se encuentran medidos en unidades de logaritmo de razón de probabilidades por lo tanto se deben transformar a odds-ratio y siempre las interpretaciones son ceteris paribus. La interpretación más utilizada es en término de probabilidades, 
aumentando la probabilidad de no divulgar información financiera en un 17\% / 18,5\%. No obstante para el ejercicio 2016, dicha situación es diferente ya que la relación no es estadísticamente significativa.

Los argumentos teóricos e investigaciones empíricas han demostrado el impacto de los determinantes políticos en las políticas públicas, no obstante la alineación política no ha sido tenida en cuenta con frecuencia por la literatura como determinante de la DIF. En este caso una de las interpretaciones posibles es que las autoridades de los GLBA alineadas políticamente con el gobierno provincial poseen menores incentivos para divulgar información financiera.

La diferencia de resultados de los modelos entre el ejercicio 2013 y 2016 podría ser explicada por el efecto predisposición de la coalición política gobernante de divulgar información financiera en internet, es decir que la variable "alineación política" podría estar mezclando el efecto alineación con el efecto "coalición política gobernante" ya que las elecciones de año 2015 cambiaron la coalición política gobernante en la provincia.

H5: A medida que aumenta el tamaño se incrementa la probabilidad de divulgar información financiera pública: Los resultados de los modelos de regresión lineal y logística 1.1, 1.2, 2.1, 2.2 y 2.3, en línea con los argumentos teóricos y los resultados empíricos de la literatura, sugieren una relación positiva y estadísticamente significativa entre el tamaño del municipio y la variable dependiente, tanto medido en habitantes (modelo 1.1, 2.1 y 2.3) como en ingresos presupuestarios (modelos 1.2 y 2.2).

Los resultados de los modelos 1.1, 2.1 y 2.3 sugieren que el aumento de la participación de la población sobre el total del GLBA, para el tramo que va desde el municipio menos poblado (1.764 habitantes) al municipio con la media de la población (116.605 habitantes), incrementa la probabilidad de divulgar información financiera entre un $1,78 \%$ y $7,73 \%$, y para el tramo que va de la media al municipio más poblado (1.775.816 habitantes), la aumentaría entre un 44,28\% y 70,30\%.

Respecto de la variable participación de ingresos presupuestarios sobre el total del GLBA, los resultados de los modelos 1.2 y 2.2 sugieren que el aumento de la misma, para el tramo que va desde el municipio con menor presupuesto ( $\$ 19.882$ - en

calculando la exponencial de los coeficientes y luego calcular probabilidades concretas probando distintos escenarios. 
miles) al municipio con presupuesto promedio ( $\$ 342.803$ - en miles), incrementa la probabilidad de divulgar información financiera entre un $7,66 \%$ y $12,47 \%$, y para el tramo que va de la media al municipio con mayor presupuesto ( $\$ 2.629 .615$ - en miles), la aumentaría entre un $34,83 \%$ y $56,18 \%$.

La fuerte heterogeneidad del tamaño (población y presupuesto) de los GLBA se ve reflejada en los resultados de los modelos, los cuales aportan valores consistentes.

Una interpretación posible es que a mayor cantidad de habitantes existen mayores asimetrías de información entre el gobernante y los ciudadanos, generando mayor demanda de información por parte de la ciudadanía. Por otro lado si medimos la participación de ingresos presupuestarios sobre el total de ingresos de todos los GLBA podríamos interpretar que los GLBA con más presupuesto poseen mayores y mejores capacidades de utilizar medios tecnológicos para divulgar información financiera.

Por último pareciera que la medición del tamaño se encuentra más ajustada a la realidad mediante los ingresos del GLBA que con la cantidad de habitantes.

H7: A medida que aumenta el acceso a internet se incrementa la probabilidad de divulgar información financiera pública: Los resultados del modelo 1.3, en línea con los argumentos teóricos y los resultados empíricos de la literatura, sugieren una relación positiva y estadísticamente significativa entre el porcentaje de hogares con PC y la divulgación de información financiera. Cabe señalar que la variable porcentaje de hogares con PC se encuentra correlacionada con las variables de tamaño pudiendo esta situación impactar en los resultados de los modelos.

El resultado del modelo 1.3 sugiere que el aumento de la participación de hogares con PC del mínimo (30,95\%) a la media (44.62\%) aumentaría la probabilidad de divulgar información financiera en un 20,81\%, y el incremento de la media al máximo $(70,92 \%)$ incrementaría dicha probabilidad en un $42,81 \%$. Dichos resultados sugieren que a medida que la participación de hogares con PC aumenta, se incrementa la probabilidad en forma creciente. Al igual que con la variable tamaño, los resultados de los modelos de regresión logística y de regresión lineal para la variable \% de hogares con PC son consistentes entre sí.

Una interpretación posible sería que el acceso a internet por parte de los ciudadanos aumenta los incentivos para utilizar dicho medio para comunicarse entre las autoridades del GLBA y los mismos. 


\section{Conclusiones}

La DIF de los GLBA en la presente investigación fue planteada bajo los postulados de la teoría de agencia, en donde el equilibro de poderes entre cada principal y cada agente dio como resultado distinta calidad y cantidad de DIF, y bajo otras teorías como la institucional, la de legitimidad y la de elección publica las cuales complementan el análisis y dan origen a distintos matices en la difusión de información financiera.

Por otro lado se planteó el teorema de la descentralización, el cual identifica beneficios de la misma, los cuales solo se dan en un contexto de transparencia de la información. Por último, desde un enfoque teórico, se citaron los principios de responsabilidad fiscal, los cuales dan el marco para una gestión eficiente.

La información disponible en internet sobre la ejecución presupuestaria de los 135 GLBA de los ejercicios económicos 2013 y 2016 fue medida mediante variables binarias. La heterogeneidad de la DIF de los GLBA dio origen a la presente investigación la cual planteó la necesidad de responder la incógnita ¿Cuáles son los determinantes de la DIF de los GLBA?. Para responderla se relevaron los principales determinantes que propone la literatura de los cuales se eligieron siete determinantes, cinco de ellos surgen de un estudio meta-analítico el cual aportó evidencia sobre la significatividad de los mismos (intereses, transferencias, competencia política, tamaño y ingresos promedio), otro del relevamiento de la literatura (acceso a internet) y un séptimo poco utilizado en la literatura empírica sobre determinantes de DIF (la alineación política de la coalición política local con la provincial).

En base a la literatura existente, se plantearon tres modelos para indagar sobre evidencia que soporte las hipótesis planteadas, aplicados al ejercicio 2013 y 2016. Cabe destacar que los resultados de los modelos planteados pueden encontrarse afectados por posibles problemas de medición y problemas de variables omitidas.

En el caso del periodo 2013, los resultados de los modelos planteados indicarían que el tamaño, el acceso a internet y la alineación política poseen una relación estadísticamente significativa con la DIF siendo su signo positivo para los dos primeros y negativo para el caso de la alineación política. Los resultados de los modelos del ejercicio 2016 sugieren que el tamaño se relaciona positivamente con la DIF y que dicha relación es estadísticamente significativa.

Identificar los determinantes de DIF puede contribuir a la implementación de estrategias que promuevan una mayor transparencia de la información financiera 
mediante el uso de tecnologías de información de manera de satisfacer las demandas sociales más efectiva y eficientemente, diseñando sistemas de información gubernamental más transparentes, democráticos y participativos. De este modo los ciudadanos estarán mejor informados y podrán tener un rol más activo en el seguimiento de las decisiones de las autoridades de los gobiernos locales, logrando una mejor administración local que contribuya al desarrollo social y económico.

Comprender el modelo que explica el comportamiento de las instituciones, puede contribuir a plantear políticas que reduzcan los desvíos, en este caso los resultados sugieren que los GLBA menos poblados o con bajos recursos presupuestarios, la falta de acceso a internet y los GLBA que se encuentran alineados políticamente al gobierno provincial tienden a tener una DIF más débil.

La DIF en internet de los GLBA es solo una parte de la transparencia, por lo tanto es necesario continuar con otras investigaciones que incluyan otros periodos, distintos modelos de medición de la DIF y determinantes, aspectos sobre el impacto en la eficiencia de la DIF, nuevas reglas de responsabilidad fiscal que promuevan la participación y el control ciudadano, entre otras posibles investigaciones. 


\section{Referencias}

Las referencias marcadas con "* " indican estudios incluidos en un estudio metanalítico.

Archel, P., J. Husillos, C. Larrinaga, and C. Spence. (2009). Social Disclosure, Legitimacy Theory and the Role of the State. Accounting, Auditing \& Accountability Journal 22(8): 1284-1307.

Argañaraz N., S. Devalle, S. Celdrán, J. Pilatti (2011) Índice de Visibilidad Fiscal Municipal IARAF 2011: En promedio, es baja la visibilidad de las cuentas públicas en los portales web de municipios argentinos. Serie: Estudios y Propuestas Número 3/Septiembre 2011. IARAF, Córdoba.

*Baber, W. R. (1983). Toward understanding the role of auditing in the public sector. Journal of Accounting and Economics, 5, 213-227.

*Baber, W.R., Sen, P.K. (1984). The role of generally accepted reporting methods in the public sector: An empirical test. Journal of Accounting and Public Policy 3 (2), 91106.

Baber, W. R. and A. K. Gore. (2006). Consequences of GAAP Disclosure Regulation Evidence from Municipal Debt Issues. http://papers.ssrn.com/sol3/papers.cfm? abstract_id $=942786$.

Banker, R. D. \& Patton, J. M. (1987). Analytical agency theory and municipal accounting: An introduction and an application. Research in Governmental and Nonprofit Accounting, 3 (Part B), 29-50.

Barletta, M. (2012) Determinantes políticos de la conducta fiscal subnacional: el caso de los municipios de la provincia de Buenos Aires (Tesis de maestría). Maestría en Finanzas Públicas Provinciales y Municipales. UNLP.

Buchanan, J. M. (1984). The Theory of Public Choice II. eds. JM Buchanan and RD Tollison, Ann Arbor: University of Michigan Press.

*Caba Pérez, C., P. Rodríguez Bolívar, M., y López Hernández, A. M. (2008). eGovernment process and incentives for online public financial information. Online Information Review, 32(3), 379-400.

*Cárcaba García, A. C. y García, J. G. (2008). Determinantes de la divulgación de información contable a través de Internet por parte de los gobiernos locales. Spanish Journal of Finance and Accounting/Revista Española de Financiación y Contabilidad, 37(137), 63-84. 
Centro de Estudios para los Nuevos Desafíos - CENUD - (2015). El gobierno abierto en municipios de la provincia de Buenos Aires - Informe Final - Pcia de Bs. As. Secretaria general de la gobernación - Consejo federal de inversiones.

Chan, J. L. y Rubin, M. A. (1987). The role of information in a democracy and in government operations: the public choice methodology. Research in Governmental and Nonprofit Accounting, 3(Part B), 3-27.

*Cheng, R. H. (1992). An Empirical Analysis of Theories on Factors Influencing State Government Accounting Disclosure. Journal of Accounting and Public Policy 11: $1-42$.

Collin, S. O. Y., Tagesson, T., Andersson, A., Cato, J. y Hansson, K. (2009). Explaining the choice of accounting standards in municipal corporations: Positive accounting theory and institutional theory as competitive or concurrent theories. Critical perspectives on Accounting, 20(2), 141-174.

*Copley, P. A. (1991). The Association between Municipal Disclosure Practices and Audit Quality. Journal of Accounting and Public Policy 10(4): 245-266.

Debreceny, R., Gray, G. and Rahman, L. (2002), The determinants of internet financial reporting, Journal of Accounting \& Public Policy, Vol. 21 Nos 4/5, pp. 371-94.

Diéguez, G., Gasparín, J. M., Sánchez, J. y Schejtman, L. (2015). Escenarios y perspectivas del gobierno electrónico en América Latina y el Caribe. Documento de Trabajo $N^{\circ}$ 132. CIPPEC, Buenos Aires.

FMI (2001), Manual de Transparencia Fiscal.

García García, J. G., Magdaleno, M. I. A. \& Magdaleno, M. L. A. (2016). Determinantes de la transparencia en municipios de mediano y pequeño tamaño. Auditoría Pública, (67), 51-60.

Garriga, M. y Rosales, W. (2013). Finanzas públicas en la práctica. Selección de casos y aplicaciones. 1a ed. E-Book- La Plata: EDULP.

*Giroux, G. (1989). Political interests and governmental accounting disclosure. Journal of Accounting and Public Policy, 8(3), 199-217.

*Giroux, G. y D. Deis. (1993). Investor Interest and Government Accounting Disclosure. Accounting, Auditing and Accountability Journal 63(1): 63-78.

*Giroux, G. y A. J. McLelland. (2003). Governance Structures and Accounting at Large Municipalities. Journal of Accounting and Public Policy 22(3): 203-230. 
Gómez Villegas, M. y Montesinos Julve, V. (2014). Gobierno electrónico y transparencia financiera y presupuestal de los departamentos en Colombia. Revista Venezolana de Gerencia, 19(68).

*Gore, A. K. (2004). The Effects of GAAP Regulation and Bond Market Interaction on Local Government Disclosure. Journal of Accounting and Public Policy 23(1): 2352.

Gulayin, D. J. (2014). Divulgación de información financiera del sector público provincial y municipal de la Provincia de Buenos Aires (Trabajo final integrador). Especialización en administración financiera y control del sector público. Facultad de Ciencias Económicas de la UNLP.

Ho, A. (2002). Reinventing Local Governments and the E-Government Initiative. Public Administration Review 62(4): 434-444.

*Ingram, R. W. (1984). Economic incentives and the choice of state government accounting practices. Journal of Accounting Research, 126-144.

*Ingram, R. W., \& DeJong, D. V. (1987). The effect of regulation on local government disclosure practices. Journal of Accounting and Public Policy, 6(4), 245-270.

Kaufmann, D., Kraay, A. y Pablo Zoido Lobaton, P. Z. (1999). Governance Matters: The World Bank Development Research Group Macroeconomics and Growth and World Bank Institute. Governance, Regulation and Finance.

Kaufmann, D., Kraay, A. y Mastruzzi, M. (2003). Government matters III: governance indicators for 1996-2002. Draft forcomment, The World Bank.

Kopits, G. (2000). Calidad de gobierno: Transparencia y responsabilidad. In BID, Conferencia sobre transparencia y desarrollo en América Latina y el Caribe, Buenos Aires, Argentina.

*Laswad, F., Fisher, R. y Oyelere, P. (2005). Determinants of voluntary Internet financial reporting by local government authorities. Journal of Accounting and Public Policy, 24(2), 101-121.

Lüder, K. (1992). A Contingency Model of Governmental Accounting Innovations in the Political-Administrative Environment. Research in Governmental and Nonprofit Accounting 10: 99-127.

Lüder, K. (1994). The 'contingency model' reconsidered: experiences from Italy, Japan and Spain. Perspectives on performance measurement and public sector accounting, 1-15. 
Lüder, K. (2002). Research in Comparative Governmental Accounting over the last decade -Achievements and Problems-. En: V. Montesinos y J.M. Vela (Eds) Innovations in Governmental Accounting. Kluwer Academic Publishers.

Ministerio de Economía de la Provincia de Buenos Aires. (2014). Municipios de la provincia de Buenos Aires: Evolución de la situación económico financiera 20072013.

Nacke, M., Calamari, M., Fernández Arroyo, N y Pando, D. (2012). Índice Nacional de Páginas Web Municipales 2012. Documento de Trabajo, (101). CIPPEC.

*Robbins, W. A. y Austin, K. R. (1986). Disclosure quality in governmental financial reports: An assessment of the appropriateness of a compound measure. Journal of Accounting Research, 412-421.

Rodríguez Bolívar, M. P., Alcaide Muñoz, L. y López Hernández, A. M. (2013). Determinants of financial transparency in government. International Public Management Journal, 16(4), 557-602.

Rosales, W. (2005). Aplicación de la Ley de Responsabilidad Fiscal a la Nación, sus Provincias y Municipalidades. 38 Jornadas Internacionales de Finanzas PúblicasUniversidad Nacional de Córdoba. UNLP.

Oates, W. E. y Jimenez, P. P. (1977). Federalismo fiscal. Instituto de estudios de administración local.

Oates, W.E. (2005) Toward A Second-Generation Theory of Fiscal Federalism. International Tax and Public Finance, 12, 349-373.

Pagani, M. y Pau, M. (2014). NTIC y modernización en los municipios de la provincia de Buenos Aires: Resultados de un estudio sobre sus portales web. VIII Jornadas de Sociología de la UNLP, 3 al 5 de diciembre de 2014, Ensenada, Argentina. En Memoria Académica.

Pando, D. y Fernández Arroyo, N. (comp.) (2013). El gobierno electrónico a nivel local. Experiencias, tendencias y reflexiones. CIPPEC y Universidad de San Andrés.

Porto A. y Lódola A. (2010): Resultados electorales y política económica. El conflicto rural y el resultado electoral 2009 en las municipalidades de la Provincia de Buenos Aires, Anales de la XLV Reunión Anual de la Asociación Argentina de Economía Politica.

Porto, A., Rosales W. y Tortarolo D. (2012) La calidad de la Administración Tributaria como insumo de la función de producción recaudatoria en Alberto Porto 
(Coordinador) Capítulo del Libro Temas de Economía de los Gobiernos Municipales. Editorial Dunken.

Sanguinetti, P., Brassiolo, P., Ortega, D., Álvarez, F., Quintero, L., Berniell, L., De la Mata, D., y Maris, L. (2015). Reporte de Economía y Desarrollo 2015: Un Estado más efectivo. Capacidades para el diseño, la implementación y el aprendizaje de políticas públicas. Bogotá: CAF.

Sanguinetti, P., Sanguinetti, J. y Tommasi, M (2001) La conducta fiscal de los gobiernos municipales en Argentina: los determinantes económicos, institucionales y políticos. Maestría en Finanzas Públicas Provinciales y Municipales, Universidad Nacional de La Plata.

*Serrano Cinca., C., Rueda Tomas., M. y Portillo Tarragona, P. (2009). Factors influencing e-disclosure in local public administrations. Environment and planning C: Government and Policy, 27(2), 355-378.

Stock, J. H., y Watson, M. W. (2012). Introduction to econometrics: Global edition. Boston, MA: Pearson Education.

*Styles A. K. y Tennyson M. , (2007) The accessibility of financial reporting of u.s. municipalities on the internet, Journal of Public Budgeting, Accounting \& Financial Management, Vol. 19 Issue: 1, pp.56-92.

Suchman, M. C. (1995). Managing Legitimacy: Strategic and Institutional approaches. Academy of Management Review 20(3): 571-610.

Weber, M. (1978). The Types of Legitimate Domination. Pp. 212-254 in G. Roth and C. Wittich, eds., Economy and Society. Berkeley: University of California Press.

Zimmerman, J. L. (1977). The municipal accounting maze: An analysis of political incentives. Journal of Accounting Research, 107-144. 